\title{
Intrinsic Connections of Macaque Striate Cortex: Afferent and Efferent Connections of Lamina $4 \mathbf{C}^{1}$
}

\author{
DAVID FITZPATRICK, ${ }^{*, 2}$ JENNIFER S. LUND $\ddagger$ AND GARY G. BLASDEL $\S^{3}$ \\ 'Department of Anatomy, Duke University, Durham, North Carolina 27710, and Departments of $\ddagger$ Psychiatry and $\S 0$ phthalmology, \\ School of Medicine, University of Pittsburgh, Pittsburgh, Pennsylvania 15261
}

\begin{abstract}
We have studied the intrinsic organization of macaque striate cortex by tracing the pattern of horseradish peroxidase (HRP)-labeled axons and cell bodies produced by microinjections of HRP into single cortical laminae. Both anterograde and retrograde transport results were used to examine: (1) the pattern of projections from lamina $4 \mathrm{C}$ to the superficial layers; $(2)$ the projection from lamina $4 C$ to deeper cortical layers; and (3) the projections to lamina $4 \mathrm{C}$ from other cortical laminae.

Laminae $4 \mathrm{C} \alpha$ and $4 \mathrm{C} \beta$ differ in their pattern of projections to the superficial layers of striate cortex. Axons from neurons in lamina $4 C \beta$ ascend through lamina $4 B$ without giving off collaterals and terminate in lamina $4 A$ and in the base of lamina 3. By contrast, axons from neurons in lamina $4 \mathrm{C} \alpha$ terminate in lamina $4 B$ and less densely in the $4 A / 3 B$ region.

The projection from lamina $4 \mathrm{C} \beta$ to lamina $4 A$ is particularly dense and is distributed in a patchy fashion immediately above each injection site. The projection from lamina $4 \mathrm{C} \beta$ to lamina 3B appears less dense and more widespread; we estimate that individual $4 \mathrm{C} \beta$ axons may spread laterally for more than $400 \mu \mathrm{m}$. Furthermore, the pattern of HRP-labeled cell bodies in lamina $4 C \beta$ following injections into laminae 4A and $3 B$ provides evidence for a subdivision within $4 C \beta$. These injections always produce a large number of labeled neurons in the upper part of lamina $4 C \beta$, whereas the lower portion contains few labeled neurons that are located immediately under the center of the injection site.

Both lamina $4 \mathrm{C} \alpha$ and lamina $4 \mathrm{C} \beta$ also contribute less dense projections to the deeper layers of cortex. Lamina $4 \mathrm{C} \beta$ projects mainly to lamina 6 , whereas lamina $4 \mathrm{C} \alpha$ contributes axon terminals to both lamina $5 \mathrm{~A}$ and lamina 6 .

Neurons in lamina 6 provide the bulk of the intracortical projections to lamina $4 \mathrm{C}$. The axons of these neurons are fine in caliber and have a delicate side-spine morphology that is quite distinct from lateral geniculate axon arbors. Neurons in lamina $5 \mathrm{~A}$ also project onto lamina $4 \mathrm{C}$, but the projections of these neurons appear concentrated in lamina $4 \mathrm{C} \alpha$.
\end{abstract}

Received February 19, 1985; Revised May 22, 1985;

Accepted May 22, 1985

${ }^{1}$ This work was supported by National Institutes of Health Grants EY03321 and EY05282 to J. S. L. and G. G. B., and Grant EY05543 to D. F. We wish to thank Kathryn Cowart, Kathy Ludden, and Tom Harper for technical assistance, and Susan Havrilcsky for preparing the manuscript.

${ }^{2}$ To whom correspondence should be addressed.

${ }^{3}$ Present address: Department of Physiology, University of Calgary, Calgary, Alberta Canada T2N-1M4.
These results confirm or refine many conclusions about intrinsic connections of striate cortex drawn from Golgi material and suggest new patterns of connections not suspected from previous work.

The key to understanding cortical function lies in establishing the way in which inputs from the thalamus and other brainstem regions are transformed into the response properties of output neurons. Although we are still far from understanding the nature of this complex process, it is clear that the achievement of this objective will require a detailed knowledge of intracortical circuitry and the relation of this circuitry to afferent and efferent cell groups.

The macaque striate cortex provides an excellent system for the study of intracortical circuitry because of the remarkable degree of laminar segregation of different afterent and efterent pathways. For example, inputs from the magnocellular and parvocellular laminae of the lateral geniculate nucleus (LGN) terminate in separate and largely nonoverlaping tiers within lamina $4 \mathrm{C}$ with magnocellular afferents occupying a more superficial position (lamina $4 \mathrm{C} \alpha$ ) than parvocellular ones (lamina 4C $\beta$ ) (Hubel and Wiesel, 1972; Hendrickson et al., 1978). Likewise, the efferent projections to various extrastriate regions and to different subcortical targets arise from populations of neurons that are segregated into different layers (Lund et al., 1975; Rockland and Pandya, 1979; Tigges et al., 1981).

In addition to a precise laminar arrangement of afferents and efferents, the striate cortex also possesses a high degree of order in the horizontal dimension. Perhaps the best known example of this order is the segregation of the terminations from individual geniculate laminae into alternating bands ( $400 \mu \mathrm{m}$ wide), each band receiving input solely from one eye (Hubel and Wiesel, 1972, 1977). This feature provides the substrate for ocular dominance columns that have been identified physiologically (Hubel and Wiesel, 1968). More recent demonstrations of regularly arrayed, patchy, geniculate projections to lamina 3, and patchy patterns of neurons projecting to area 18 and the middle temporal area further emphasize the structured nature of afferent and efferent connections in monkey striate cortex (Tigges et al., 1981; Fitzpatrick et al., 1983; Livingstone and Hubel, 1984).

Most of our knowledge about the intrinsic organization of monkey striate cortex is based on studies that used the Golgi method (Valverde, 1971; Lund, 1973; Lund and Boothe, 1975). These studies have provided important insights into the organization of striate cortex, but due to the nature of the method, they have supplied a somewhat fragmentary picture of the pattern of axonal connections within and between laminae. In the present series of experiments, we have injected small amounts of horseradish peroxidase (HRP) into individual cortical laminae in order to study the interlaminar and intralaminar connections of small populations of neurons. By exam- 
ining patterns of orthogradely labeled axonal processes and retrogradely labeled cell bodies, we have confirmed or refined many of the conclusions drawn from the Golgi material and have found new patterns of connections not suspected from previous work.

Our observations are divided into two sections. In the present paper we examine the intracortical connections of lamina $4 C$, a layer which receives most of the input from the LGN and whose projections are confined to the striate cortex. In the following paper (Blasdel et al., 1985) we examine the interconnections of the remaining layers which constitute the source of projections to the thalamus, brainstem and to extrastriate cortex. Some of these results have been reported briefly (Blasdel et al., 1983; Lund et al., 1983).

\section{Materials and Methods}

General methods. Six macaque monkeys (four Macaca fascicularis, two Macaca nemestrina) were anesthetized with ketamine, intubated, and then placed in a stereotaxic head frame. They were respirated with an oxygen/ nitrous oxide mixture at a rate sufficient to maintain end-tidal carbon dioxide within normal limits. As the initial dose of ketamine wore off, the animals were gradually switched to halothane and nitrous oxide anesthesia. In cases where we recorded from an animal prior to injecting HRP, we used Pentothal $(0.5$ to $2.0 \mathrm{mg} / \mathrm{kg} / \mathrm{hr}$ ) in conjunction with nitrous oxide $(60 \%)$ to provide anesthesia; the animal was then paralyzed with an intravenous infusion of pancuronium bromide. Some of the animals used in these studies also participated in other, previously reported experiments (Blasdel and Fitzpa. trick, 1984).

Microinjections. Following surgical preparation, we drilled a number of small holes in the cranium and reflected the underlying dura. Two approaches were used to locate specific laminae. One relied on extracellular recordings (see Blasdel and Fitzpatrick, 1984, for details) to determine the upper and lower boundaries to lamina $4 \mathrm{C}$. These in turn allowed us to estimate (by extrapolation from the surface) the depths of particular laminae. The other approach entailed making many laterally spaced injections at systematically varied depths - a "shotgun" approach — that enabled us to achieve a spectrum of 100 - to $150 \cdot \mu \mathrm{m}$-wide microinjections at varying depths.

We made approximately 100 injections which were confined to the exposed outer operculum of striate cortex. Forty of these were examined in detail. Each injection was initiated by advancing the broken tip (5- to $10-\mu \mathrm{m}$ diameter) of an HRP-filled micropipette through the pia overlying the targeted part of striate cortex. The HRP solution in the tip consisted of 10 to $20 \%$ HRP dissolved in $0.9 \%$ saline with 0.1 to $0.5 \%$ polyornithine. We then used a stepping motor microdrive (California Institute of Technology. Central Engineering Services) to advance the pipette into the brain. After the pipette had been advanced to an appropriate depth, we passed a small, continuous, anodal current $(0.5$ to $1 \mu \mathrm{A})$ for 5 to $10 \mathrm{~min}$. The pipette was then removed and the entire procedure was repeated at a different location.

Histology. Following a 1- to 2-day survival period, animals were deeply anesthetized with Nembutal and perfused through the heart with warm phosphate-buffered saline followed by a fixative solution containing $2 \%$ paraformaldehyde and $1 \%$ glutaraldehyde in $0.1 \mathrm{~m}$ phosphate buffer. This

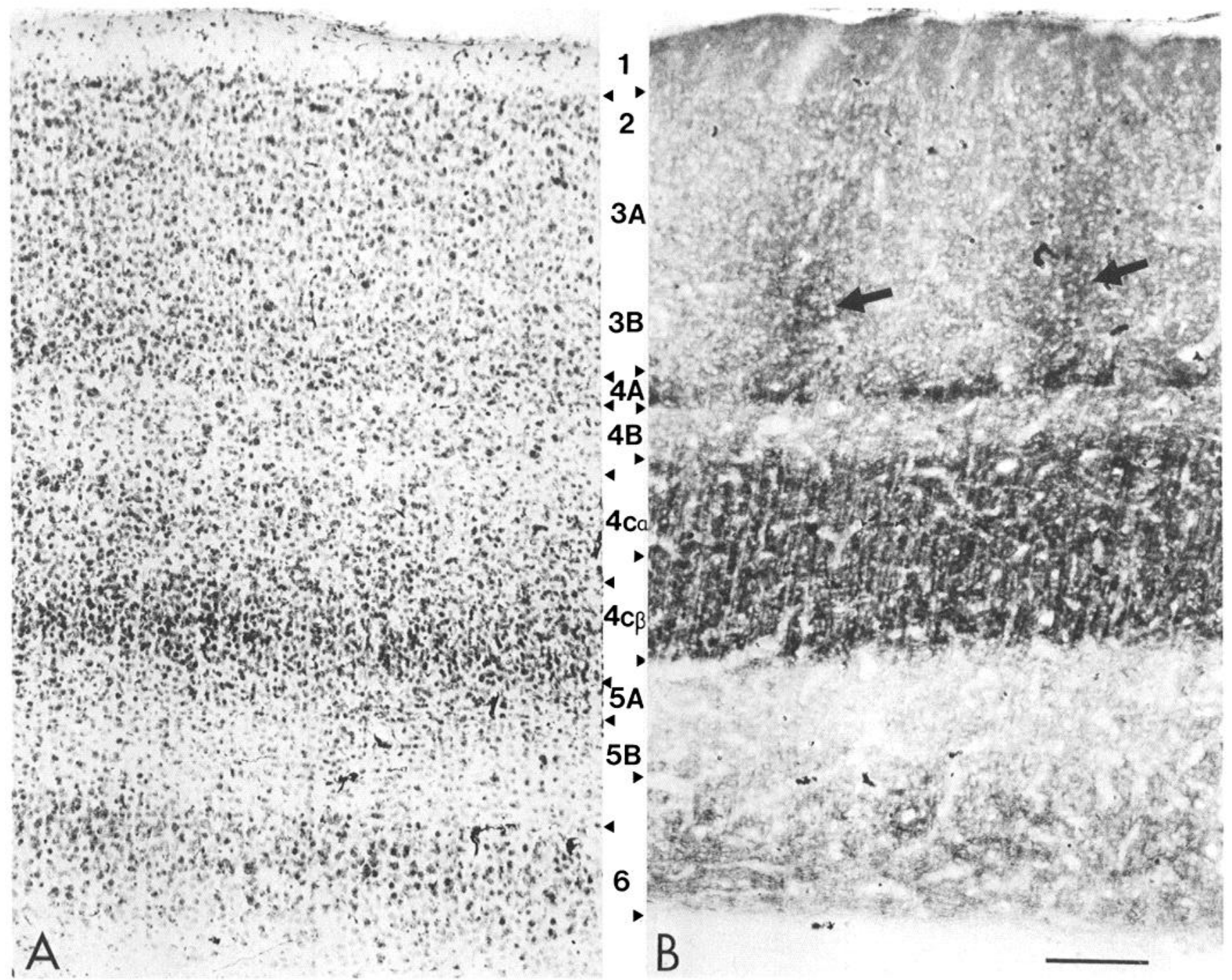

Figure 1. Comparison of Nissl-stained $(A)$ and cytochrome oxidase-reacted $(B)$ sections through striate cortex in the macaque. The laminar borders used in this study are indicated (see the text for more details). Scale bar $=200 \mu \mathrm{m}$. 
was followed with a single rinse of $10 \%$ sucrose in phosphate buffer. Brains were placed in a buffered solution of $30 \%$ sucrose until they sank. They were then sectioned at $40 \mu \mathrm{m}$ on a freezing microtome. Cut sections were reacted either with benzidine dihydrochloride, according to the procedure of de Olmos (1977), or according to the cobalt-intensified diaminobenzidine procedure of Adams (1977). in some cases we reacted alternate sections with each technique in order to compare sensitivity. For some animals, alternate sections were stained for Nissl substance (using either cresyl violet or neutral red) or for cytochrome oxidase to aid in the identification of cortical laminae.

\section{Results}

The laminar numbering system used in this and the following paper (Blasdel et al., 1985) is shown in Figure 1. Since certain laminar borders do not appear sharp in Nissl-stained sections, we have used the distribution of cytochrome oxidase activity, as well as cytoarchitecture, to define laminar borders (see Blasdel and Fitzpatrick, 1984, for further discussion). Cytochrome oxidase staining is a useful criterion for defining laminar borders since its distribution accurately reflects the location of geniculate terminations (see summary diagram, Fig. 2). We define lamina $4 \mathrm{C}$ as the wide zone of intense cytochrome oxidase activity in the middle of cortex. This zone is roughly divided in two, the upper half being $4 \mathrm{C} \alpha$ and the lower half, $4 \mathrm{C} \beta$. Lamina $4 \mathrm{~B}$ is defined as the cytochrome-poor band immediately above lamina $4 \mathrm{C}$, and lamina $4 \mathrm{~A}$ is defined as the thin strip of intense cytochrome oxidase activity ariayed in a reticular network (Fig. 3) immediately above lamina 4B. The laminae above $4 \mathrm{~A}$ are defined according to the system of Lund et al. (1975)

Before describing the results of the HRP microinjections, a few words about our presentation of the data are in order. In our descriptions we use the expression "distance from the radial axis of the injection site" as a way of comparing the lateral extent of neurons or fibers labeled by HRP injections into different layers. The radial axis refers to a line drawn through the center of the injection site in such a fashion that it follows the columnar trajectory of most axon trunks projecting between lamina $€$ as well as the apical dendrites of pyramidal neurons. Since most injections produced labeled cell bodies and terminals that extended symmetrically about this axis, the distance from the axis is about one-half the total distance over which labeled cell bodies and terminals were found.

in some cases, the plane of section was slightly oblique to the radial axis, so that the full pattern of interlaminar conncctions cannot be seen in individual sections. Our summary diagrams were assembled by surveying a complete series of sections through the injected region to assure that they illustrate the total pattern of anterograde or retrograde transport. However, the photomicrographs may show only that portion of the projection pattern visible in a single section.

Finally, we have chosen to arrange the presentation of the data so as to address three basic issues: (1) the projection of lamina $4 \mathrm{C}$ to more superficial cortical layers; (2) the projection of lamina $4 \mathrm{C}$ to deeper cortical layers; and (3) the projections to lamina $4 \mathrm{C}$ from other cortical layers. This organization provides a framework for relating both retrograde and anterograde transport evidence to the origin and termination of specific intracortical pathways.

\section{Projections of lamina $4 \mathrm{C}$ to superficial cortical layers}

\section{Retrograde transport results}

The effects of injecting HRP into layers above $4 C$ are shown in chart form in Figure 4 and in the photomicrographs in Figures 5 to 8. Following injections of HRP into layers 2 and $3 A$ (Figs. $4 A$ and 5), labcled neurons are found in laycrs $4 \mathrm{~B}$ and 5 , but not in layer $4 \mathrm{C}$. Indeed, in the photomicrograph (Fig. 5), bundles of labeled axons are seen streaming through lamina $4 C$, but no labeled neurons are present. In contrast, injections of HRP into lamina 4A/3B consistently produced labeled neurons in lamina $4 C$ (Figs. $4 B, 6$, and 7). Labeled neurons in lamina $4 \mathrm{C}$ are found immediately under the injection site, and with small injections (Fig. 6), the labeled neurons are largely confined to the width of the injection site. Labeled neurons are present throughout the depth of laminae $4 \mathrm{C} \alpha$ and $4 \mathrm{C} \beta$.

The pattern of retrograde cell body labeling found in lamina $4 \mathrm{C} \beta$ following injections of $\mathrm{HRP}$ into lamina $4 \mathrm{~A} / 3 \mathrm{~B}$ provides evidence for a subdivision within lamina $4 C \beta$. Injections of HRP into lamina 4A/ $3 \mathrm{~B}$ always produced labeled neurons within the upper part of $4 C \beta$. But in some injections, the neurons in the lower part of lamina $4 \mathrm{C} \beta$



Figure 2. Summary diagram of the pattern of lateral geniculate terminations in striate cortex. $l$, input from intercalated layers; $P_{1}, P_{2}$, and $P_{3}$, input from parvocellular layers; $M$, input from magnocellular layers-perhaps two components (Hubel and Wiesel, 1972; Hendrickson et al., 1978; Blasdel and Lund, 1983; Fitzpatrick et al., 1983). The ocular dominance bands are indicated as dashed lines 400 to $500 \mu \mathrm{m}$ apart. 


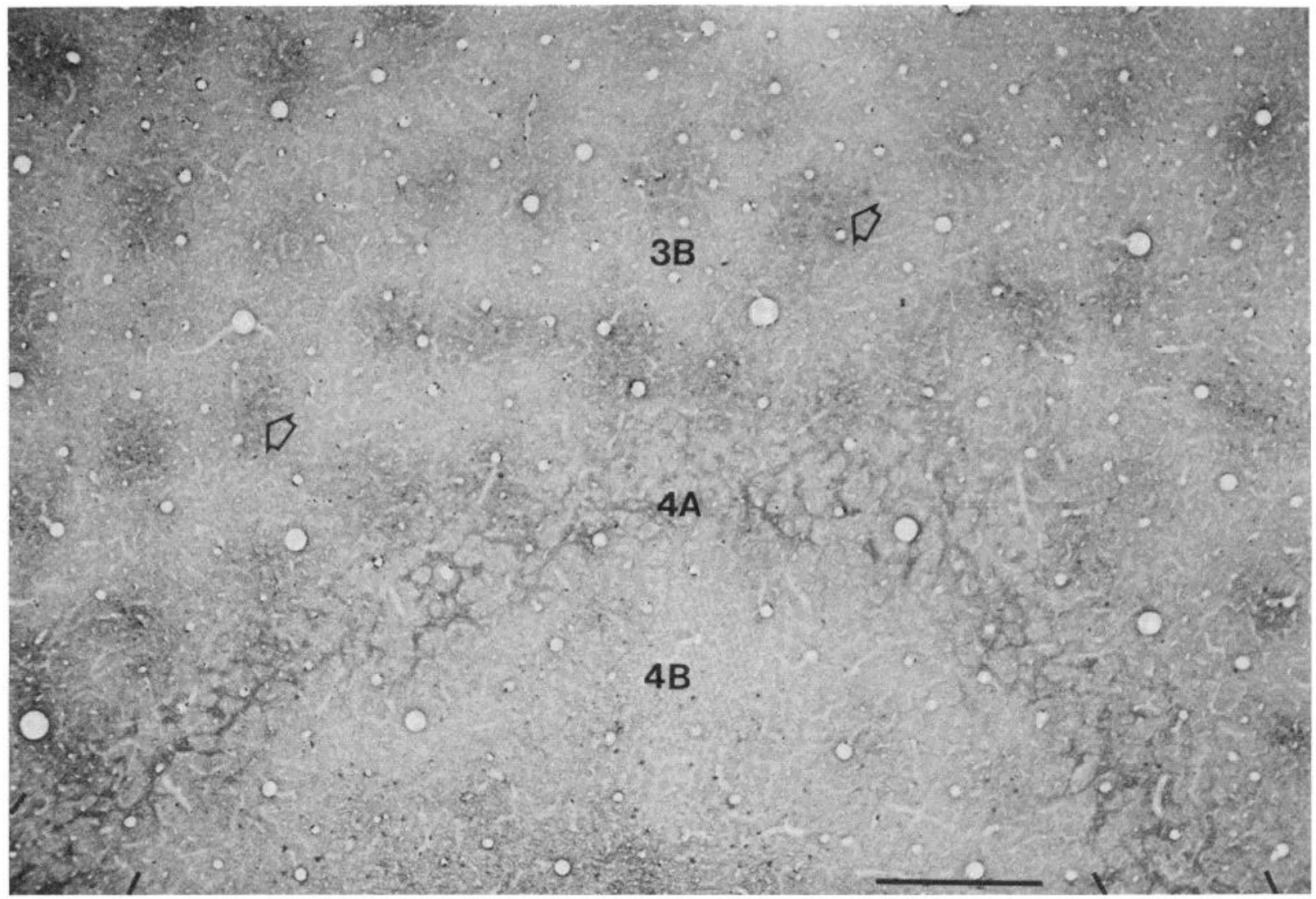

Figure 3. Tangential section through layers $3 \mathrm{~B}, 4 \mathrm{~A}$, and $4 \mathrm{~B}$ of macaque striate cortex stained for cytochrome oxidase. This photomicrograph emphasizes the reticulated nature of the cytochrome oxidase-rich geniculate terminal zone in lamina $4 \mathrm{~A}$, as well as the patchy distribution of cytochrome oxidase reactivity in lamina 3 (arrows). Scale bar $=500 \mu \mathrm{m}$.

were not labeled. Following larger injections of HRP into lamina 4A/ 3B, labeled cells were found in the lower part of lamina $4 \mathrm{C} \beta$ only under the heart of the injection site, and a conspicuous cleft was present lateral to the radial axis of the injection site (Figs. $4 B$ and 7 ). From an analysis of adjacent sections stained with cytochrome oxidase, it is clear that this zone of unlabeled neurons lies within the cytochrome-rich region and is therefore a subdivision of lamina $4 \mathrm{C} \beta$. The exact nature of the difference between upper and lower portions of lamina $4 \mathrm{C} \beta$ cannot be specified from these data. However, several possible alternatives are examined under "Discussion."

Injections of HRP into lamina $4 \mathrm{~B}$ without involvement of lamina $4 \mathrm{~A}$ resulted in labeled neurons immediately below the injection site in lamina $4 \mathrm{C} \alpha$ and a few neurons in the upper part of lamina $4 \mathrm{C} \beta$ (Figs. $4 \mathrm{C}$ and 8). Labeled neurons in $4 \mathrm{C} \alpha$ appear scattered around the injection site up to $500 \mu \mathrm{m}$ from the radial axis. These neurons were located mostly in the upper part of $4 \mathrm{C} \alpha$ (but within the cytochrome-rich zone).

\section{Anterograde transport results}

Lamina $4 C \beta$. Injections of HRP into lamina $4 \mathrm{C} \beta$ produce numerous labeled axon trunks, often clustered into fascicles, that travel upward to laminae $4 \mathrm{~A}$ and $3 \mathrm{~B}$ in a column often as narrow as the injection site (Figs. 9 to $13 A$ ). The labeled axons pass through lamina $4 \mathrm{~B}$ without obvious signs of termination. At the lamina 4B/4A border, the labeled axon bundles arborize and form a dense terminal plexus. This zone of terminals is most dense in lamina 4A where it coincides with the cytochrome-rich band of geniculate terminations. Within this zone, the terminals appear to be arranged in clusters about $75 \mu \mathrm{m}$ wide (Fig. 10B). This dense terminal plexus is roughly the same width as the injection site.

In addition to this dense focused projection to lamina 4A, labeled terminals are also found within lamina $3 \mathrm{~B}$. The projection to $3 \mathrm{~B}$ appears less dense, but axon trunks can be seen giving off prominent fans of terminal fibers that spread 400 to $500 \mu \mathrm{m}$ from the radial axis (Figs. 9 and 11). Assuming that the most laterally placed trunks produce the most laterally reaching arbors in these superficial layers, each trunk would appear to contribute an arbor that terminates over a region approximately $400 \mu \mathrm{m}$ in diameter (in agreement with the arbor sizes of Golgi-impregnated axons for these cells; see Fig. 15 in Lund, 1973). With some injections, coarse trunks may be seen to emerge from the fan in lamina $3 \mathrm{~B}$ and travel laterally. They give rise to laterally placed clusters of terminals in $3 B$ which may lie as far as $550 \mu \mathrm{m}$ away from the radial axis (Figs. 9 and 12). A summary of the orthograde transport results from HRP injections into lamina $4 C \beta$ appears in Figure $13 A$.

Lamina $4 \mathrm{C} \alpha$. Injections of HRP into lamina $4 \mathrm{C} \alpha$ do not produce the prominent and dense pattern of terminal labeling in lamina $4 \mathrm{~A} /$ $3 \mathrm{~B}$ that occurs after injections into lamina $4 \mathrm{C} \beta$. Instead, the most dense zone of labeled terminals is found in lamina $4 \mathrm{~B}$ immediately above the injection site, extending roughly 250 to $300 \mu \mathrm{m}$ from the radial axis (Fig. 14). A less dense population of labeled fibers, including beaded axon components, extend into laminae $4 \mathrm{~A}$ and 3B. In addition, labeled axons are found traveling laterally within $4 \mathrm{C} \alpha$ and rising diffusely into 4B. These axons can be traced up to $1 \mathrm{~mm}$ from the radial axis. A summary of the results of $\mathrm{HRP}$ injections into lamina $4 \mathrm{C} \alpha$ is shown in Figure $13 B$.

\section{Projections of lamina $4 \mathrm{C}$ to deeper cortical layers}

\section{Retrograde transport results}

The pattern of retrogradely labeled neurons in lamina $4 \mathrm{C}$ following injections of HRP into laminae 5 and 6 is shown in Figure 15. Injections into either lamina 5 or lamina 6 produce labeled neurons in lamina $4 \mathrm{C}$. These neurons are most prevalent in lamina $4 \mathrm{C} \alpha$ and 


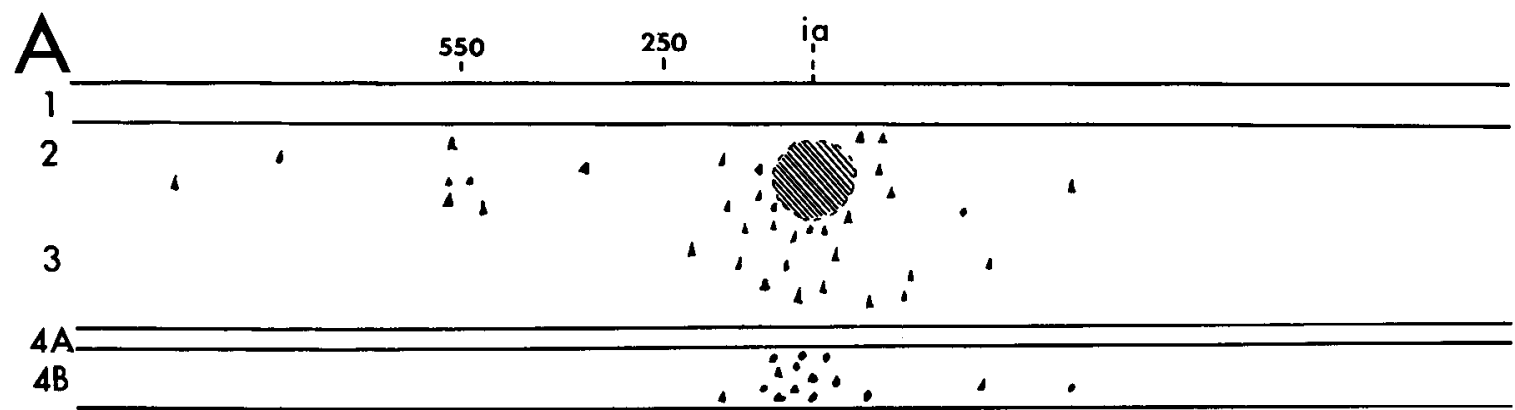

$4 \mathrm{C} a$

$4 \mathrm{C} \beta$



6

11
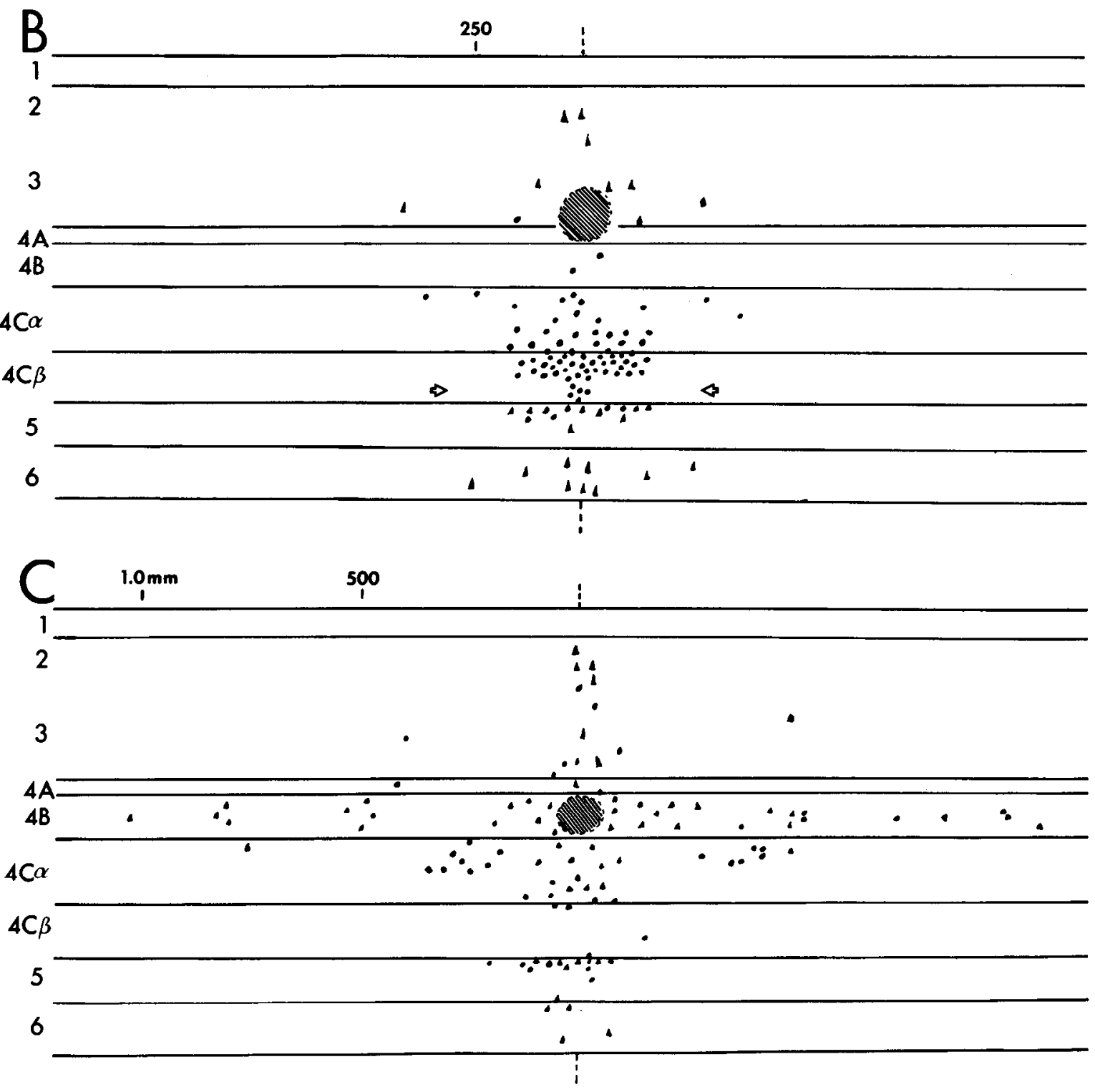

Figure 4. Summary diagrams showing the distribution of labeled neurons in striate cortex (dots or triangles) following HRP microinjections (hatched



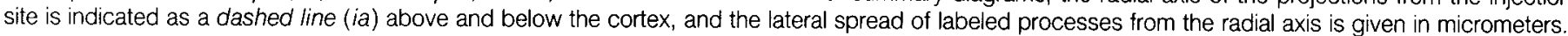






Figure 5. Photomicrograph showing an injection site in laminae 2 and $3 A$. Labeled neurons and terminals densely fill lamina 4B (arrow) and lamina 5 , whereas only labeled fibers are seen traversing lamina 4 C. Scale bar $=200$ $\mu \mathrm{m}$.

in the most superficial portion of $4 \mathrm{C} \beta$. A photomicrograph of labeled neurons in lamina $4 \mathrm{C} \alpha$ following an injection into layer 6 is shown in Figure 16. The presence of labeled neurons in these layers cannot be the result of labeling axons which are leaving the cortex since these layers do not contain projection neurons. However, it could be argued that injections into lamina 5 label the axons of $4 \mathrm{C} \alpha$ neurons that project to lamina 6 . The anterograde transport results to be described next provide support for a projection from lamina $4 \mathrm{C} \alpha$ to both layers 5 and 6 .

\section{Anterograde transport results}

Following injections of HRP into lamina $4 \mathrm{C} \alpha$, labeled fibers descend vertically through lamina $4 \mathrm{C}$ to lamina 5 where they arborize laterally, largely within the upper portion of lamina 5 , which has been designated lamina 5A (Lund et al., 1975) (Figs. 13B and 14). Labeled terminals in lamina $5 \mathrm{~A}$ are most prominent immediately beneath the injection site, but some fibers have been seen to extend up to 400 $\mu \mathrm{m}$ laterally. Descending trunks continue into lamina 6 where they give rise to a terminal field directly under the injection site as well as sparsely distributed lateral connections. A summary of the results of injections into lamina $4 \mathrm{C} \alpha$ is shown in Figure $13 B$.

Injections of HRP into lamina $4 \mathrm{C} \beta$ produce a sparse projection to lamina 6 immediately beneath the injection site (Figs. 11 and 17A). Labeled fibers from lamina $4 \mathrm{C} \beta$ appear to pass through lamina 5 without producing terminals (Figs. 11 and 17). The projection to lamina 6 is most dense within $150 \mu \mathrm{m}$ of the radial axis; however, additional scattered fibers can be seen to reach as far as 500 to $600 \mu \mathrm{m}$ laterally. The presence of labeled terminals in lamina 6 following injections into lamina $4 \mathrm{C} \beta$ seems inconsistent with our failure to see labeled neurons in lamina $4 \mathrm{C} \beta$ following injections of HRP into lamina 6 (Fig. 15, $A$ and $B$ ). There are several possible explanations for this discrepancy, and these will be examined under "Discussion." A summary of the results of injections into lamina $4 C \beta$ is shown in Figure $13 A$.

With both $4 \mathrm{C} \alpha$ and $4 \mathrm{C} \beta$ injections, labeled neurons as well as terminals are found in lamina 6 (to be described below). Although some of the labeled terminals and fibers may be collaterals of labeled pyramidal cells in this layer, we have been able to trace individual fibers from lamina $4 \mathrm{C}$ into lamina 6 where they were seen to give rise to terminal swellings. Thus, we are confident that $4 \mathrm{C}$ neurons send axons to lamina 6 which end directly beneath the injection site. Whether these neurons are the source of more laterally spreading labeled axons remains to be determined.

\section{Projections to lamina $4 \mathrm{C}$ from other cortical layers}

\section{Retrograde transport results}

Injections of $\mathrm{HRP}$ into laminae $4 \mathrm{C} \alpha$ and $4 \mathrm{C} \beta$ consistently produced labeled neurons in lamina 6 (Figs. 11 and 17). Many of these lamina 6 neurons appear to be pyramidal cells and, in some cases, apical dendrites could be seen rising from the cells and extending through lamina 5 into $4 \mathrm{C}$. Most of the labeled neurons were located immediately under the injection site. Labeled neurons appeared throughout lamina 6 following injections into either lamina $4 \mathrm{C} \alpha$ or $4 \mathrm{C} \beta$.

Injections of HRP into lamina $4 \mathrm{C} \alpha$, in addition to producing labeled neurons in layer 6 , also produce labeled neurons in lamina 5, mostly in lamina $5 \mathrm{~A}$, in a band immediately beneath the injection site. As mentioned previously, there are labeled terminals in lamina $5 \mathrm{~A}$ following injections of HRP into $4 \mathrm{C} \alpha$, and this suggests that lamina $5 \mathrm{~A}$ is reciprocally connected with lamina $4 \mathrm{C} \alpha$. A summary of the distribution of labeled neurons following injections into $4 \mathrm{C} \alpha$ and $4 \mathrm{C} \beta$ is shown in Figure 18.

\section{Anterograde transport results}

HRP injections into lamina 6 produce a heavy distribution of labeled axons and terminals within lamina 4C (as well as 4A) (Figs. 19 and 21). The most dense projection in lamina 4C lies within 250 $\mu \mathrm{m}$ of the injection axis. A less dense collection of labeled axons and terminals is seen extending laterally in laminae $4 \mathrm{C} \alpha$ and $4 \mathrm{C} \beta$ up to $600 \mu \mathrm{m}$. This projection spreads more widely still in upper $4 \mathrm{C} \alpha$ (up to $1 \mathrm{~mm}$ ). A clear band of terminals is also contributed to lamina $4 \mathrm{~A}$, reaching 500 to $600 \mu \mathrm{m}$ from the radial axis. No consistent differences in the patterns of anterograde transport were noted for injections into superficial and deep portions of lamina 6 .

The morphology of layer 6 pyramidal cell efferents is clearly 




Figure 6. Low $(A)$ and high $(B)$ power photomicrographs showing the distribution of labeled neurons following an injection of HRP into lamina 3B/4A. In contrast to injections in lamina 2/3A, injections into 3B/4A produce labeled neurons in both laminae $4 \mathrm{C} \alpha$ and $4 \mathrm{C} \beta$. Scale bars $=200 \mu \mathrm{m}$.

evident in this material (Fig. 20). These axons have a delicate sidespine morphology and are quite distinct in appearance from the large beaded profiles of lateral geniculate arbors that occupy the same layers. The side-spine axons that are filled following lamina 6 injections resemble those already described in Golgi material of monkey striate cortex as forming a dense plexus in laminae $4 \mathrm{C}$ and $4 \mathrm{~A}$ and which, for this reason, were originally thought to be thalamic in origin (Valverde, 1971; Lund, 1973).

Injections of HRP into lamina 5 produce a pattern of labeled terminals in lamina $4 \mathrm{C}$ that resembles, in overall spread, the pattern found after injections into lamina 6 . However, since HRP injections into lamina 5 produce labeled neurons in lamina 6 right under the injection site (see Fig. $13 \mathrm{C}$ ), it is possible that the labeled terminals in laminae $4 \mathrm{C} \alpha$ and $4 \mathrm{C} \beta$ are derived from HRP-filled lamina 6 neurons. A summary of the patterns of labeled fibers following injections into laminae 5 and 6 are shown in Figure 21.

\section{Discussion}

We have shown that microinjections of HRP into different laminae of the striate cortex produce unique and reproducible patterns of cell body and axonal labeling in regions outside the injection site.
Before discussing the significance of these findings and their relation to previous studies, it is essential to consider the reliability of the HRP method for identifying intracortical connections.

Given the well known fact that HRP can be taken up by damaged axons of passage, the first question that must be addressed is whether the patterns of labeled cell bodies and axons demonstrated in this study could be the result of uptake by fibers of passage. At least for fiber systems that are known to exist from other methods, retrograde labeling of cell bodies by fibers of passage does not seem to be a serious problem. For example, injections of HRP into lamina $4 \mathrm{C}$ do not label pyramidal neurons in lamina $2-3$ or the neurons in lamina $4 \mathrm{~B}$ whose axons descend through the injection site en route to extrastriate regions. This is in contrast to HRP injections in lamina 5 which produce a good number of labeled neurons in the superficial layers - a finding that is consistent with the dense projection from lamina $2-3$ to lamina 5 known to exist from previous work (Lund, 1973; Nauta et al., 1973; Lund and Boothe, 1975).

Likewise, filling of axonal trunks that pass through the injection site does not seem to contribute greatly to the pattern of anterograde transport that we see. For example, injections into lamina $4 \mathrm{C}$ do not 


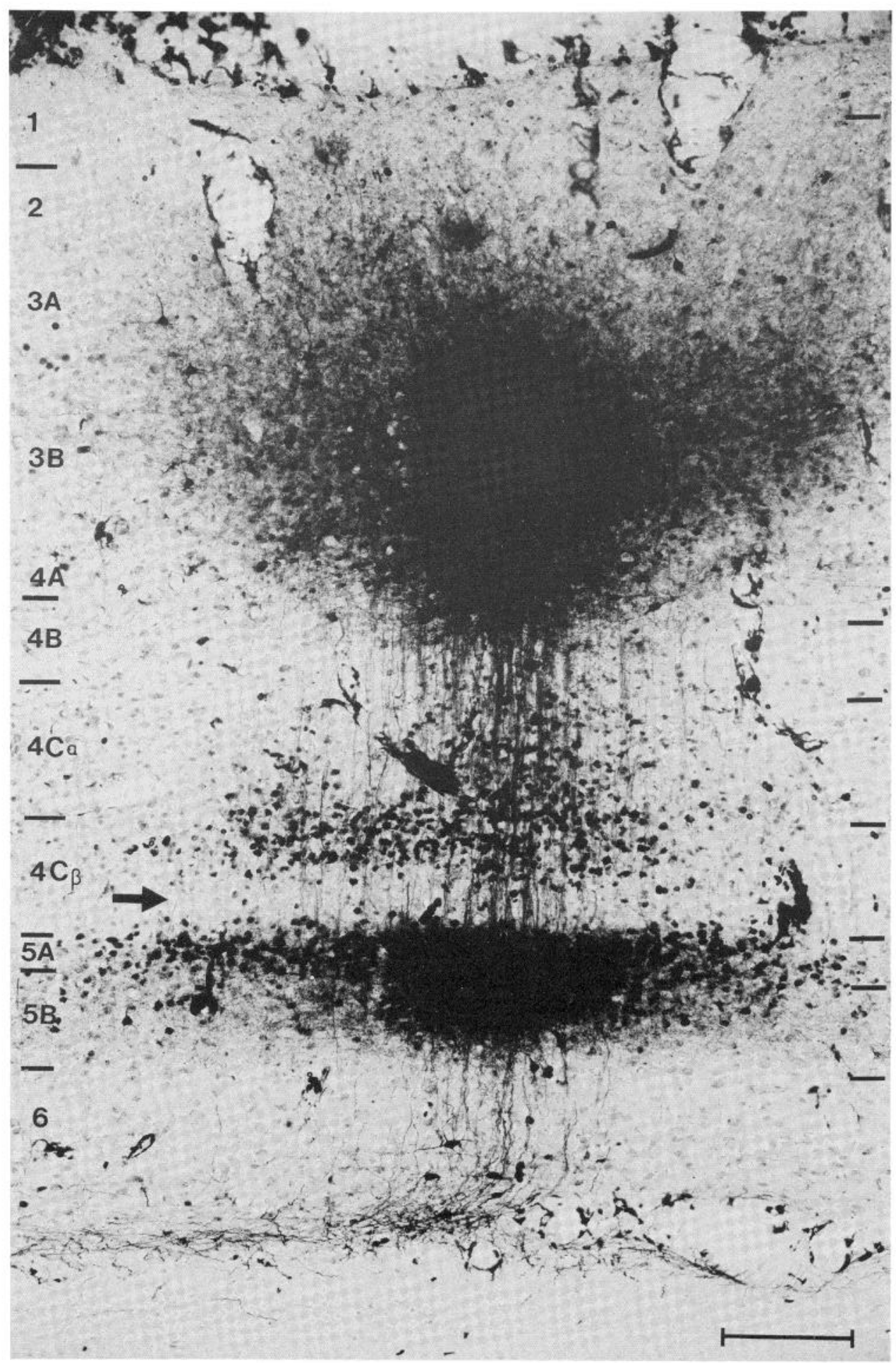

Figure 7. Photomicrograph showing the distribution of labeled neurons following a large injection of HRP which included lamina $3 B / 4 A$. Note the presence of a distinct cleft (arrow) of unlabeled neurons in lower $4 \mathrm{C} \beta$. Scale bar $=200 \mu \mathrm{m}$.

label the axons of lamina 2-3 neurons descending through lamina $4 \mathrm{C}$ into lamina 5 (see Figs. 11 and $17 \mathrm{~A}$ ).

Although these examples provide strong evidence that fibers of passage are not a problem, there are other reasons to be cautious in the interpretation of the results. Whereas known fiber systems that traverse an injection site without terminating within it do not appear to contribute to the labeling pattern, it is more difficult to assess whether filling of axon arbors that have a portion of their terminal field in the injection site might contribute to the pattern. This is particularly troubling when evaluating axon terminals in the same layer as the injection site. Since the terminal fields of single afferent axons that impinge on a layer have (in most cases) a wider spread than the width of our HRP microinjections, it is possible that the labeled processes immediately surrounding an injection site may be a mixture of local processes and those derived from other sources. Although in most cases we cannot rule out this possibility, at least one identifiable population of afferents, geniculate arbors in lamina 4C, was only rarely filled by the methods used in this study (see Blasdel and Lund, 1983).

Another issue of some concern is whether uptake by dendritic 


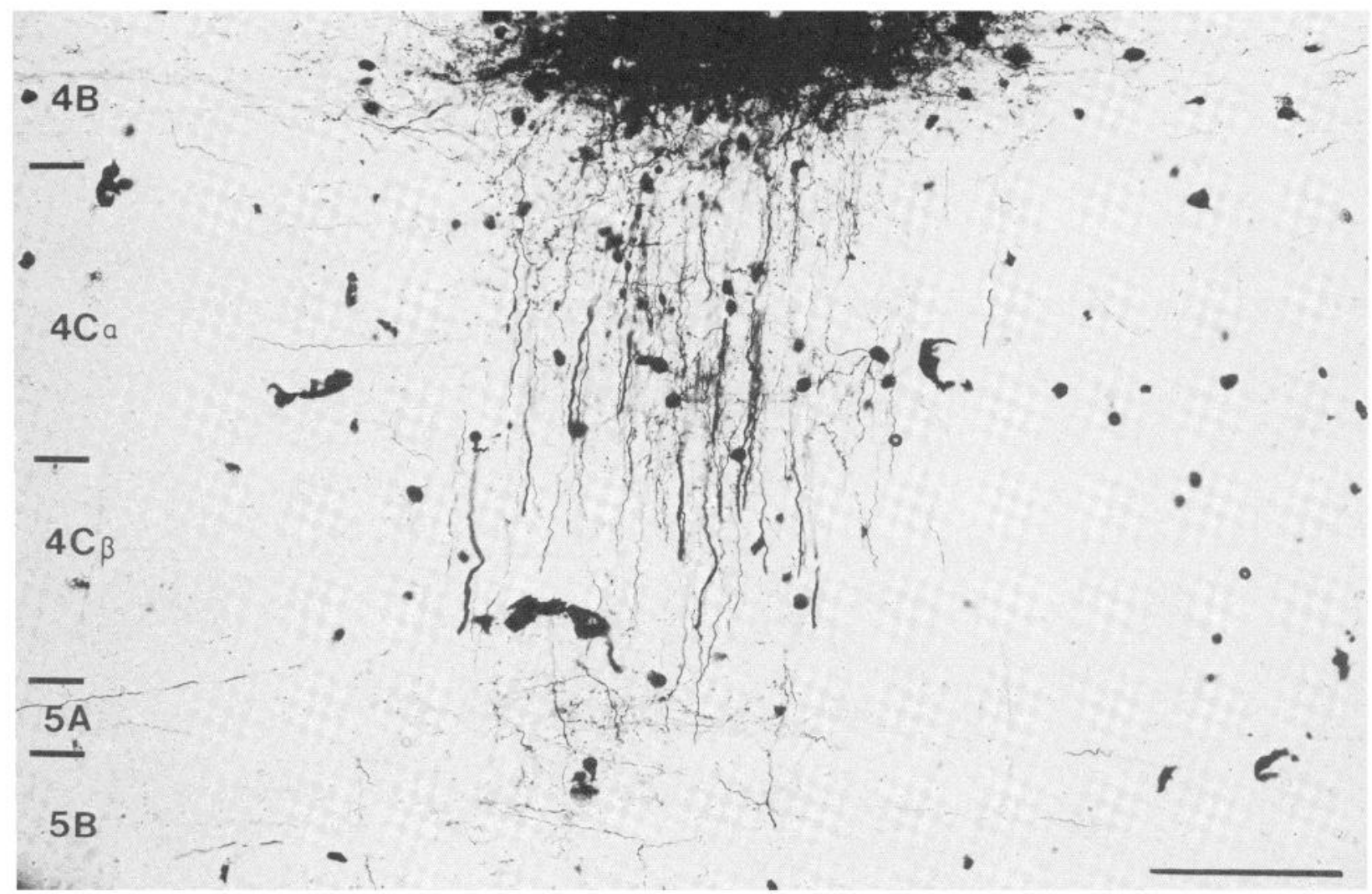

Figure 8. Photomicrograph showing the distribution of labeled cell bodies and terminals following an HRP injection into lamina 4B. Labeled neurons are abundant within lamina $4 \mathrm{C} \alpha$ but rare within lamina $4 \mathrm{C} \beta$. Note also the presence of labeled terminals in lamina $5 \mathrm{~A}$. Scale bar $=100 \mu \mathrm{m}$.

processes could contribute to the labeling patterns we have described. There is at least one clear example in which dendrites that extend into an HRP injection site do not take up a sufficient amount of HRP to label their parent somata: pyramidal neurons of lamina 5 send their apical dendrites through lamina $4 \mathrm{C}$ on their way to more superficial layers, yet these neurons are not labeled by HRP injections into lamina $4 \mathrm{C}$. In contrast, there is one pattern of HRP-labeled neurons that is difficult to explain without assuming HRP uptake by dendrites: injections of HRP into lamina 5 densely label neurons in lamina 6 immediately under the injection site, but neither Golgi studies nor our anterograde transport results provide evidence that lamina 6 neurons have a dense terminal field in lamina 5. The fact that many lamina 6 neurons have prominent dendritic arborizations in lamina 5 (Lund and Boothe, 1975) further supports the idea that dendritic uptake is responsible. The failure to see evidence for dendritic uptake by lamina 5 neurons following $4 \mathrm{C}$ injections may be due to the fact that lamina 5 neurons have apical dendrites that pass through lamina $4 \mathrm{C}$ without arborization, and, as a result, only a small percentage of their total dendritic field is exposed to HRP. Whatever the reason for the difference between these two examples, it appears that dendritic uptake may contribute to the pattern of labeled neurons produced by HRP microinjections. Therefore, we have considered both anterograde and retrograde transport evidence in drawing conclusions about specific intracortical pathways.

Finally, some consideration must be given to the sensitivity of this method for demonstrating interlaminar connections. As with all tracing experiments, labeled processes may provide evidence for the presence of afferent or efferent connections, but negative evidence is not sufficient for dismissing their presence. There may be a number of reasons for failing to detect a specific projection: for example, only a small percentage of neurons within a layer may give rise to the projection, or the diameter of the axon or the extent of the axon collaterals may make it difficult to detect. The distribution of retrogradely labeled neurons appears to be most affected by these constraints since, in several cases, the lateral extent of retrograde cell body labeling seems to underestimate the extent of projections based on anterograde transport. (Compare, for example, the retrograde and anterograde evidence for the projection from lamina $4 \mathrm{C} \beta$ to lamina $4 \mathrm{~A} / 3 \mathrm{~B}$ and from layer 6 to layer $4 \mathrm{C}$.) Furthermore, in one instance (the projection from $4 \mathrm{C} \beta$ to layer 6 ), retrograde transport results fail to demonstrate a projection that is shown by the anterograde transport results. For this reason we have relied largely on the anterograde results for descriptions of the lateral extent of connections. But even these must be viewed as minimal estimates; the actual extent of the projections may be greater.

Projections to the superficial layers. The results of this study show that lamina $4 \mathrm{C} \alpha$ and lamina $4 \mathrm{C} \beta$ differ in their pattern of projections to the superficial layers of striate cortex. Axons from neurons in $4 \mathrm{C} \beta$ ascend through lamina $4 \mathrm{~B}$ without giving off collaterals and terminate in lamina $4 \mathrm{~A}$ and in the base of lamina 3. By contrast, the axons from neurons in $4 \mathrm{C} \alpha$ terminate in lamina $4 \mathrm{~B}$ and less densely in the $4 \mathrm{~A} / 3 \mathrm{~B}$ region. Thus, as originally suggested on the basis of Golgi studies (Lund, 1973; Lund and Boothe, 1975), information derived from the magnocellular and parvocellular laminae of the LGN is processed by lamina $4 \mathrm{C}$ and distributed to different populations of cortical neurons. However, the projections of $4 \mathrm{C} \alpha$ and $4 \mathrm{C} \beta$ are not totally separate; there does appear to be some overlap within the $4 \mathrm{~A} / 3 \mathrm{~B}$ region. The projection of $4 \mathrm{C} \alpha$ neurons above lamina $4 \mathrm{~B}$ is consistent with the physiological properties of neurons in the $4 \mathrm{~A} / 3 \mathrm{~B}$ region; some of these neurons have contrast thresholds that are too low to be explained by parvocellular input alone (Blasdel and Fitzpatrick, 1984).

A major contribution of the present study is the identification of subdivisions within lamina $4 C$ which differ in the pattern of their 


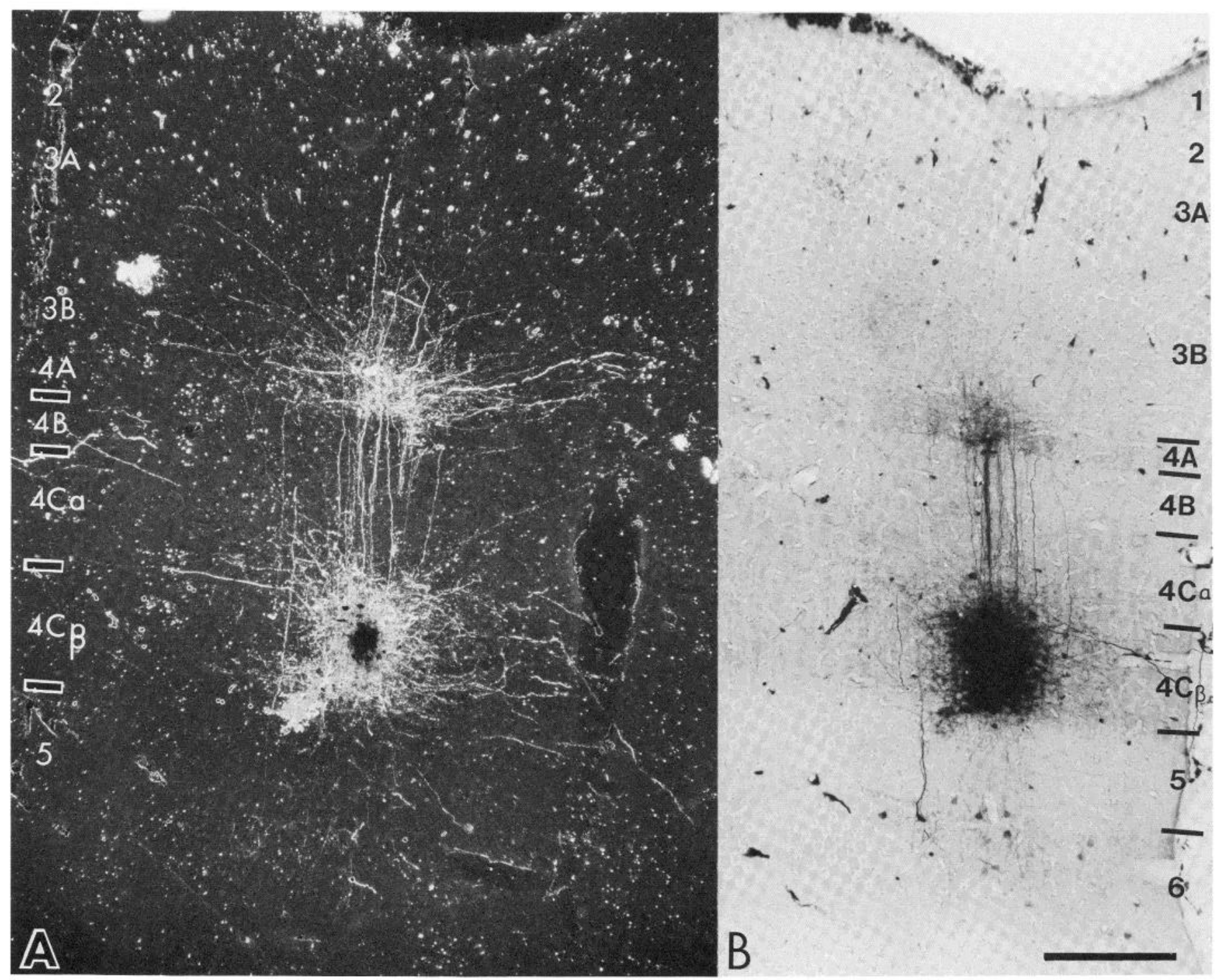

Figure 9. Brightfield $(A)$ and darkfield $(B)$ photomicrographs of adjacent sections showing the distribution of HRP-labeled neurons and terminals following injections of HRP into lamina $4 \mathrm{C} \beta$. Note prominent focus of labeled terminals in superficial layers $(3 B / 4 A)$ as well as labeled neurons in lamina $6(B)$. Scale bar (for $A$ and $B$ ) $=200 \mu \mathrm{m}$.

termination within lamina $4 \mathrm{~A} / 3 \mathrm{~B}$. Injections of $\mathrm{HRP}$ into $4 \mathrm{~A} / 3 \mathrm{~B}$ always produced labeled neurons in $4 \mathrm{C} \alpha$ and in the upper part of $4 \mathrm{C} \beta$. However, such injections yielded only a few neurons in the lower part of $4 \mathrm{C} \beta$, and these neurons were restricted to the region directly under the center of the injection site. Although we cannot currently specify the reason for this difference, it seems likely that it reflects a difference in the laminar distribution and/or horizontal extent of the axon projections from neurons in upper versus lower lamina $4 \mathrm{C} \beta$. For example, if the axons from neurons in upper $4 \mathrm{C} \beta$ spread more widely than those in the lower part, then injections of HRP into lamina $4 \mathrm{~A} / 3 \mathrm{~B}$ should label a greater number of cells in upper $4 \mathrm{C} \beta$ than in lower $4 \mathrm{C} \beta$. Likewise, if the two regions sent their axon terminals to different levels within lamina $4 \mathrm{~A} / 3 \mathrm{~B}$, it is possible that some injections would label more cells in one subdivision than in another. Indeed, given our observation of the two patterns of anterograde label in lamina $4 A / 3 B$ following injections into lamina $4 C \beta$, it is possible that the lower half of $4 \mathrm{C} \beta$ contributes the bulk of its projection to the dense patchy zone of lamina $4 \mathrm{~A}$, whereas the upper half distributes its axons more widely in lamina 3B.
Regardless of the exact nature of the difference between the upper and lower parts of lamina $4 \mathrm{C} \beta$, there are several other suggestions of a stratification within lamina $4 \mathrm{C} \beta$. Tigges and Tigges (1983) have noted in newborn squirrel monkeys that the cytochrome oxidase activity in lamina $4 \mathrm{C}$ is distributed into three tiers: a lower dark band which corresponds in width to our lower $4 \mathrm{C} \beta$; a middle light zone, corresponding to our upper $4 \mathrm{C} \beta$; and a superficial dark zone corresponding to lamina $4 \mathrm{C} \alpha$. We have found a similar pattern of cytochrome oxidase staining in infant macaque striate cortex (Fig. 22). Although not as prominent, even in the adult the level of cytochrome oxidase staining sometimes appears more dense in the lower portion of lamina $4 \mathrm{C} \beta$ than the upper portion (see, for example, Carroll and Wong-Riley, 1984). A difference in the cytochrome oxidase reactivity of upper and lower portions of $4 C \beta$ has also been shown as a result of eye enucleations (Horton, 1984). In ocular dominance columns related to the enucleated eye, cytochrome oxidase reactivity is strikingly reduced in upper $4 \mathrm{C} \beta$ whereas the lower portion of lamina $4 C \beta$ still retains a high level of cytochrome oxidase reactivity. Finally, the current source density analyses of 

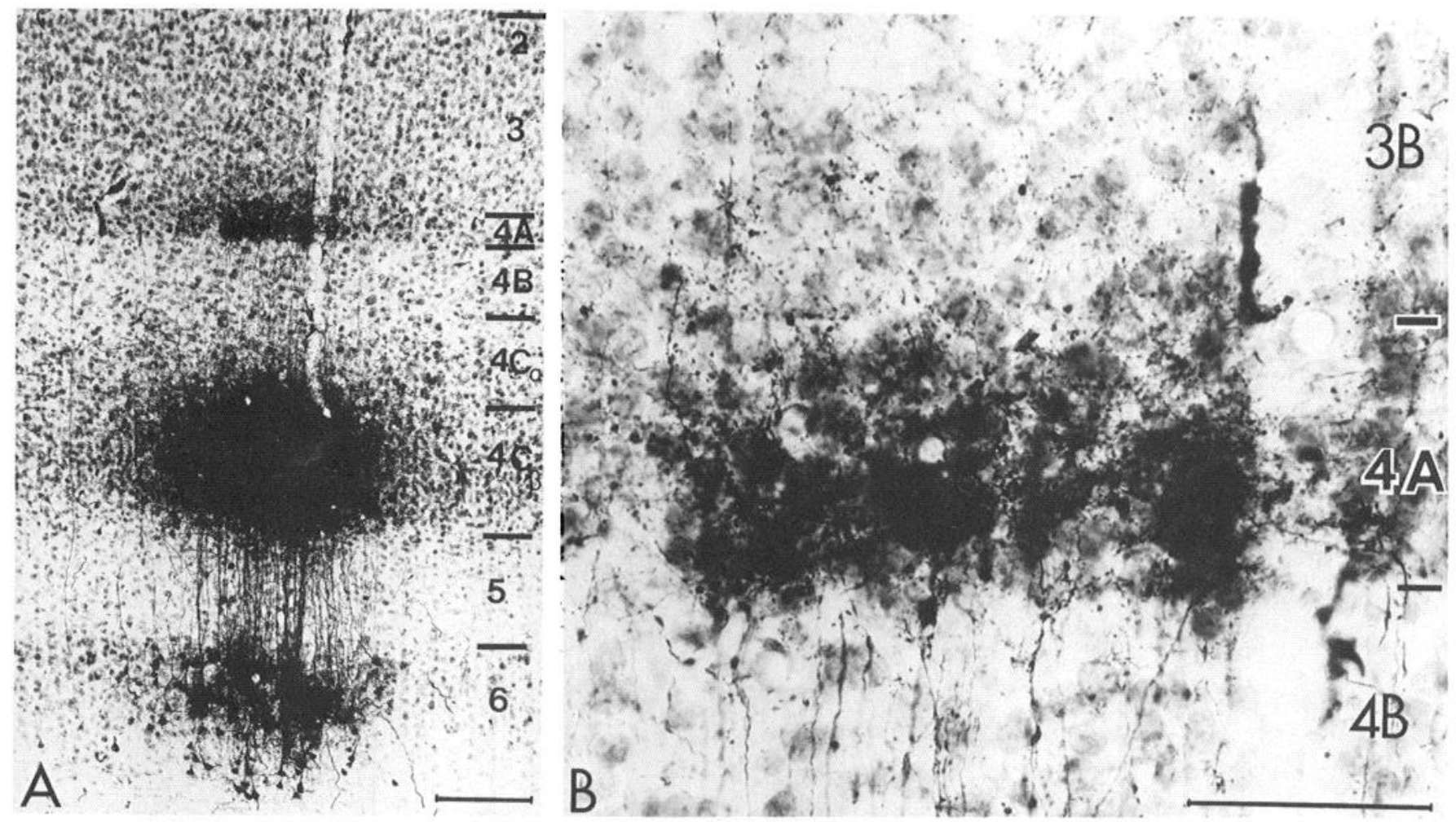

Figure 10. A, Low power photomicrograph showing the distribution of HRP-labeled neurons and terminals following a comparatively large injection of HRP into lamina $4 \mathrm{C} \beta$. The section has been counterstained with cresyl violet. Note the dense terminal field in $3 \mathrm{~B} / 4 \mathrm{~A}$ and the large number of labeled neurons in lamina 6. Laminae 5 and $4 \mathrm{~B}$ are relatively free of labeled neurons but contain a number of HRP-labeled processes. Scale bar $=200 \mu \mathrm{m}$. $(B)$ Higher power photomicrograph showing the axon terminals in lamina $4 \mathrm{~A}$ following an injection into lamina $4 \mathrm{C} \beta$. Note the dense accumulation of terminals in lamina $4 \mathrm{~A}$ and the less dense projection to lamina 3B. Scale bars $=100 \mu \mathrm{m}$.

Mitzdorf and Singer (1979) also provide support for a subdivision within lamina $4 \mathrm{C} \beta$. The results of this study suggest that upper and lower $4 \mathrm{C} \beta$ may receive projections from different populations of parvocellular neurons since neurons in upper $4 \mathrm{C} \beta$ respond to thalamic fiber stimulation with a longer latency than those in lower $4 C \beta$. Although the HRP-filled geniculocortical axons described by Blasdel and Lund (1983) had terminal fields which encompassed the whole depth of lamina $4 C \beta$, it is possible that there is an additional population, not yet detected, which innervates only a portion of lamina $4 C \beta$. Together these results provide evidence that lamina $4 \mathrm{C} \beta$ is not homogeneous across its depth but consists of two subdivisions that differ in their efferent projections, their pattern of development, their response to enucleation, and the nature of their input.

One question that remains to be addressed is the relationship between the projections from lamina $4 \mathrm{C} \beta$ and the direct projections from the LGN that terminate in lamina 4A and in the cytochromerich patches of lamina 3 . The present results show that the projections from lamina $4 \mathrm{C} \beta$ to lamina $4 \mathrm{~A}$ occupy the same stratum as the input from the parvocellular layers of the LGN. Furthermore, these projections terminate in a patchy fashion with a periodicity similar to the honeycomb pattern of LGN terminations (see Fig. 3 and Hendrickson et al., 1978). Whether this patchy pattern of terminals from lamina $4 \mathrm{C} \beta$ is complementary to or overlaps with the pattern of geniculate terminals in lamina $4 \mathrm{~A}$ remains to be determined. But one intriguing possibility is that the projections from lamina $4 \mathrm{C} \beta$ fill the holes in the honeycomb pattern of geniculate terminations.

The relation between $4 C \beta$ axons and the LGN fibers which terminate in the cytochrome-rich patches of lamina 3 is more difficult to specify. In the squirrel monkey there appears to be a cytochrome- pale zone intercalated between lamina $4 \mathrm{~A}$ and the patches in lamina 3 and it could be that the bulk of the projections from lamina $4 \mathrm{C} \beta$ terminate within this pale zone (Fitzpatrick et al., 1983; Carroll and Wong-Riley, 1984). In the macaque monkey, however, the cytochrome oxidase-rich patches appear to merge with lamina 4A, and if we take the cytochrome oxidase patches to be coincident with the terminals from the LGN, there must be overlap between geniculate and $4 \mathrm{C} \beta$ axon terminals in lamina 3B. The cytochrome-rich patches appear to extend higher into lamina $2 / 3 \mathrm{~A}$ than do the projections from lamina $4 \mathrm{C} \beta$, so that the upper portion of the patchy geniculate input zone is likely to be free of direct input from lamina $4 \mathrm{C}$. This conclusion is consistent with the observation in the squirrel monkey that HRP injections into lamina $2 / 3 \mathrm{~A}$ label neurons in the intercalated layers of the LGN without labeling neurons in lamina 4C (Fitzpatrick et al., 1983).

Projections to deeper layers. Although the major projection of lamina $4 \mathrm{C}$ neurons is to the superficial layers of the cortex, neurons within $4 \mathrm{C}$ also contribute a descending projection to layers 5 and 6 . Our anterograde evidence provides support for a descending projection from both laminae $4 \mathrm{C} \alpha$ and $4 \mathrm{C} \beta$, with the projection from $4 \mathrm{C} \alpha$ terminating in laminae $5 \mathrm{~A}$ and 6 , whereas the projection from $4 \mathrm{C} \alpha$ terminates mainly in lamina 6. Previous Golgi studies showed axons from neurons in $4 \mathrm{C} \alpha$ and $4 \mathrm{C} \beta$ descending into layer 5 , but they could not be satisfactorily traced to their terminations (Lund, 1973). Given the Golgi data and the results of our anterograde experiments, it is somewhat surprising that injections of HRP into layers 5 and 6 labeled neurons in lamina $4 \mathrm{C} \alpha$ but not $4 \mathrm{C} \beta$. This suggests that there is a difference in the nature of the descending projection from these two layers. Perhaps the descending axons from $4 \mathrm{C} \beta$ neurons are fine collaterals of axons whose principal terminal field is in lamina $4 \mathrm{~A} / 3 \mathrm{~B}$, whereas those from $4 \mathrm{C} \alpha$ contribute 
Figure 11. Photomicrograph showing the distribution of HRP-labeled axons and cell bodies following an injection into lamina $4 \mathrm{C} \beta$. This photomicrograph illustrates the dense focused projection to lamina $4 \mathrm{~A}$ and the more diffuse projection to lamina $3 \mathrm{~B}$. Note also labeled neurons and terminals in lamina 6. Scale bar $=200 \mu \mathrm{m}$.

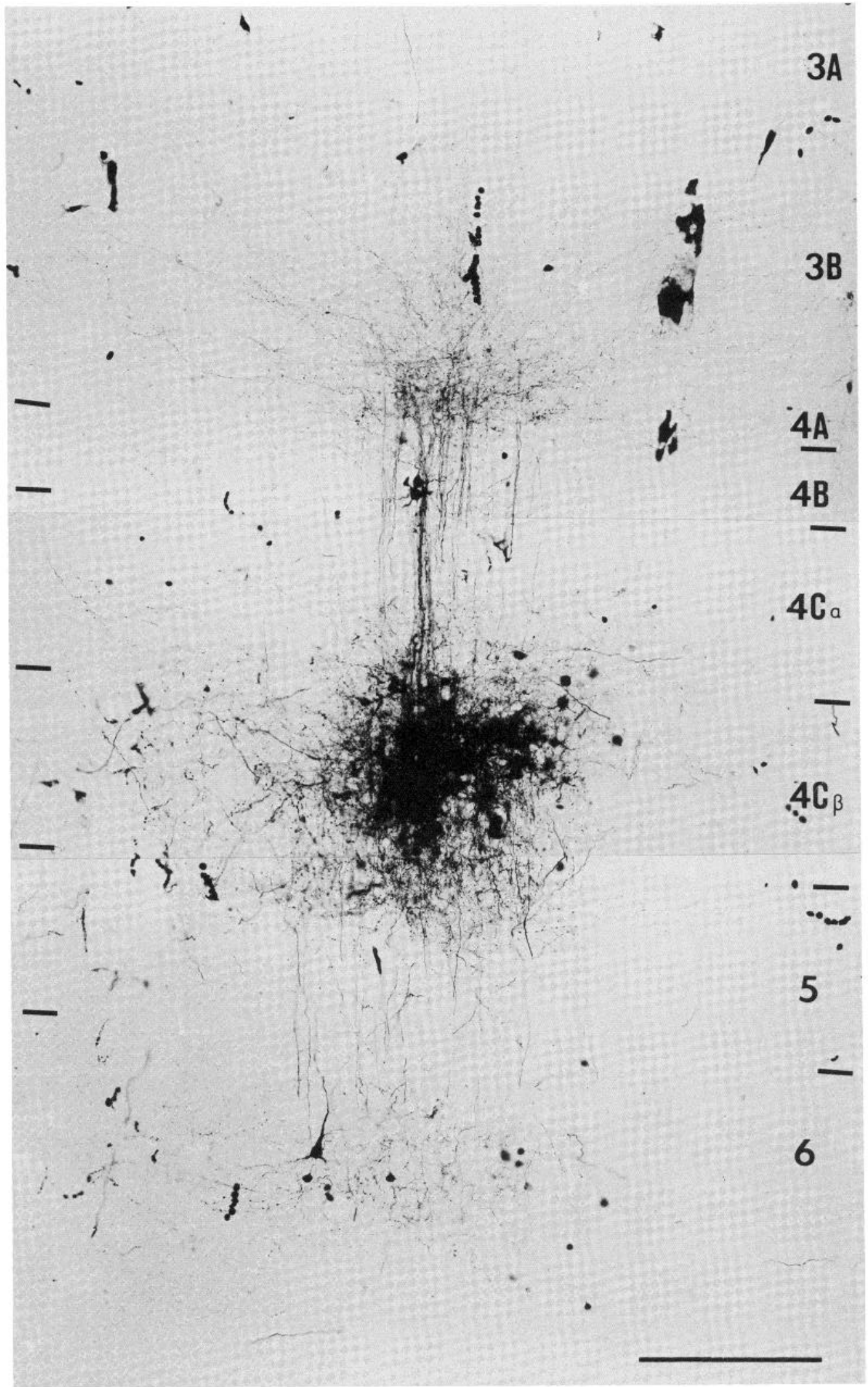




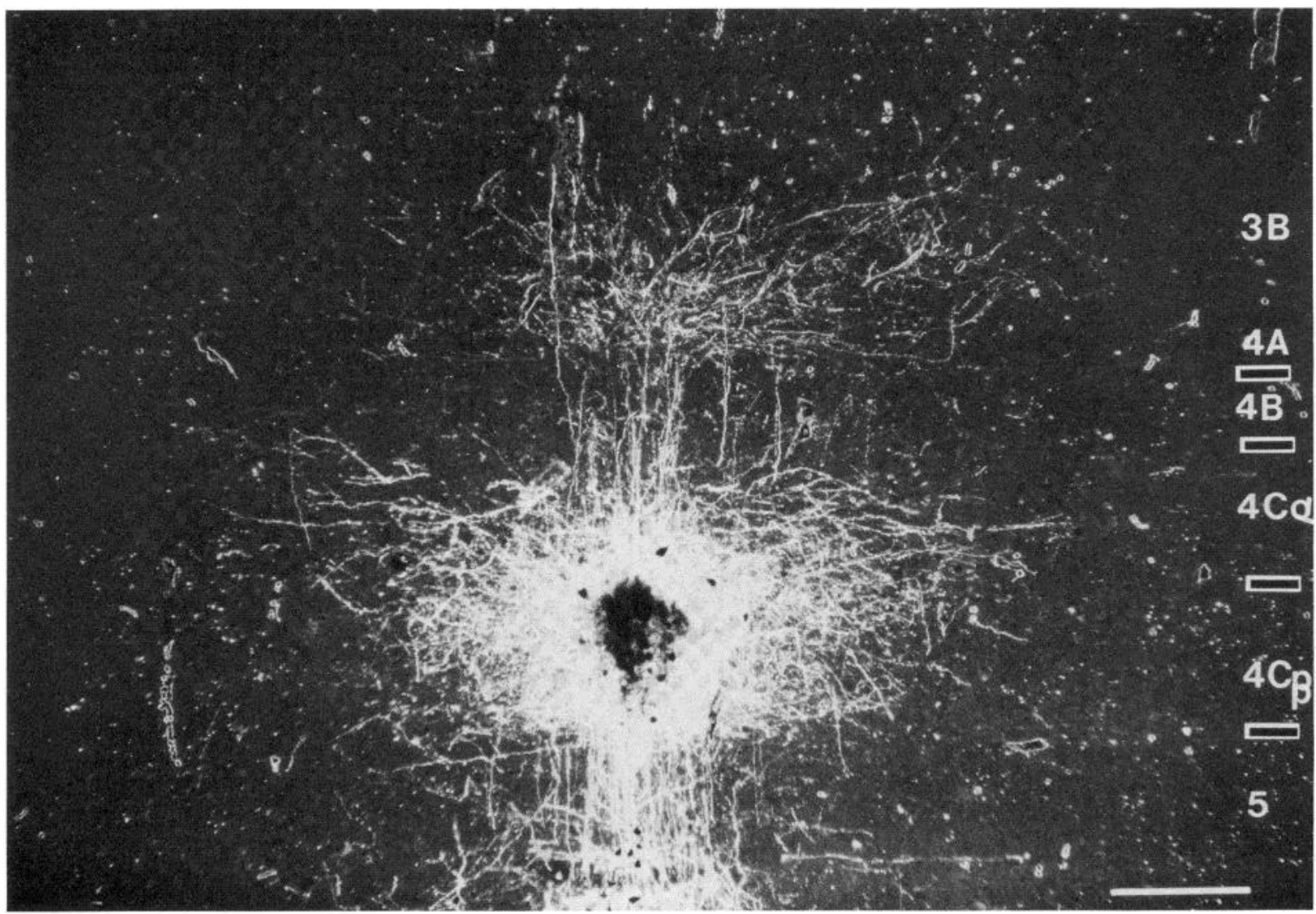

Figure 12. Photomicrograph showing labeled terminals in lamina $4 \mathrm{~A} / 3 \mathrm{~B}$ following an HRP injection into lamina $4 \mathrm{C} \beta$. In this case, the projection to lamina $3 \mathrm{~B}$ appears to include axons that travel laterally and terminate to the right of the main projection focus. Scale bar $=200 \mu \mathrm{m}$.



Figure 13. Summary diagram showing the pattern of labeled terminals following HRP injections into $4 \mathrm{C} \beta(A)$ and $4 \mathrm{C} \alpha(B)$. 


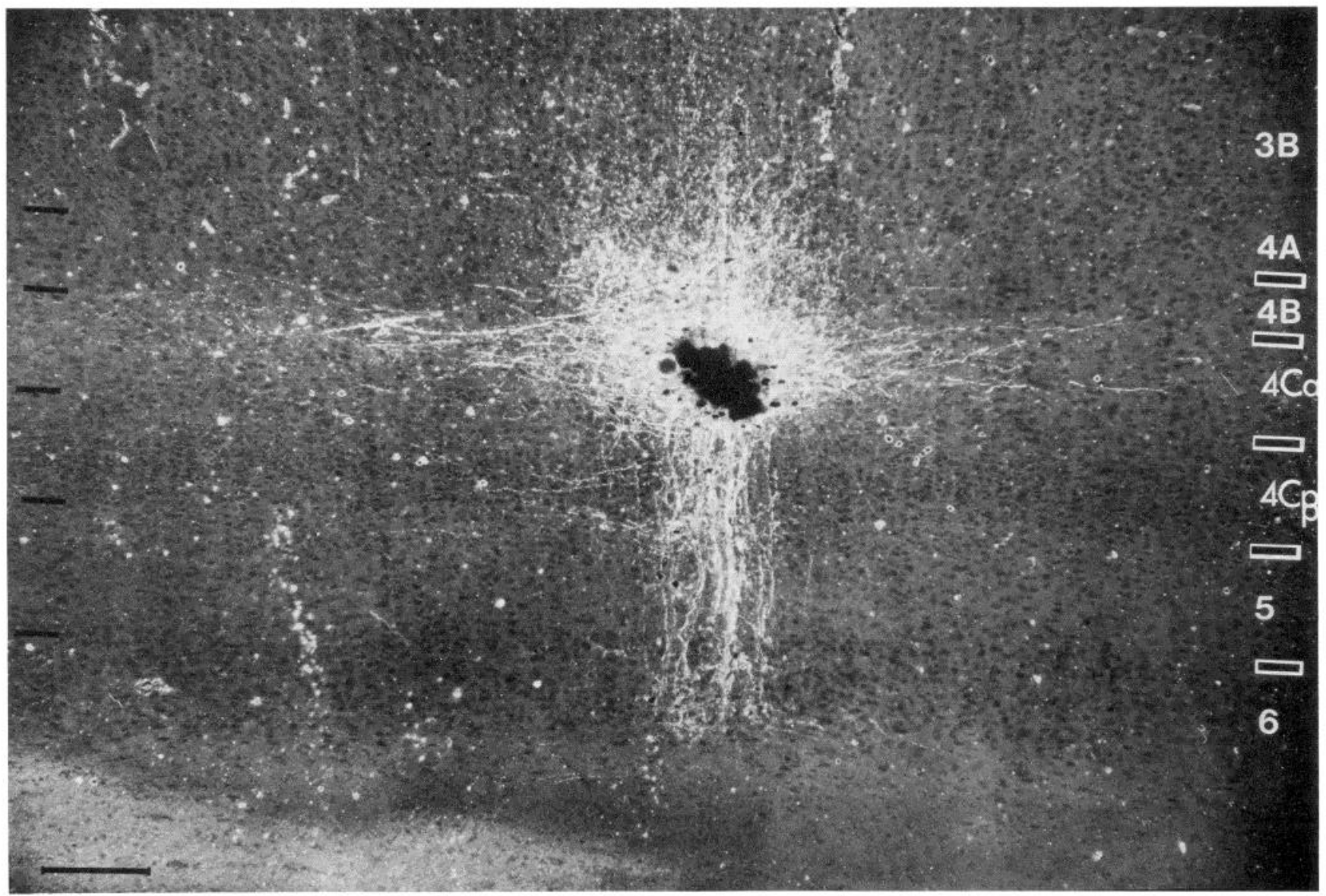

Figure 14. Darkfield photomicrograph showing the distribution of labeled fibers and terminals following an injection of HRP into lamina 4C $\alpha$. Labeled terminals are prominent in lamina $4 \mathrm{~B}$ above the injection site, but are also found in lamina 3B/4A. Note the presence of labeled axons extending laterally within $4 \mathrm{C} \alpha$ and up into $4 \mathrm{~B}$. Scale bar $=200 \mu \mathrm{m}$.

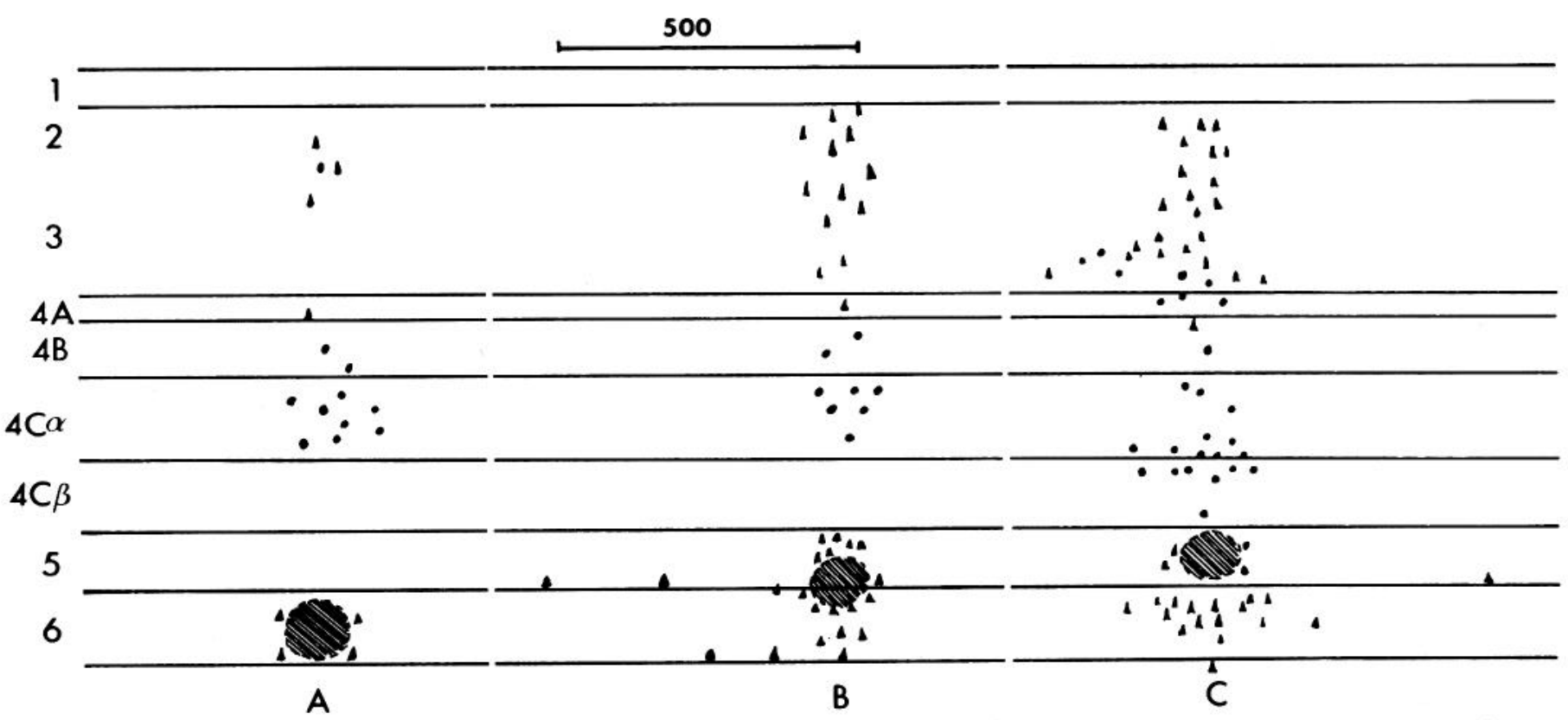
(B).

Figure 15. Summary diagram showing the pattern of labeled neurons following HRP injections into lamina $6(A)$ and lamina $5(C)$ and on the $5-6$ border 


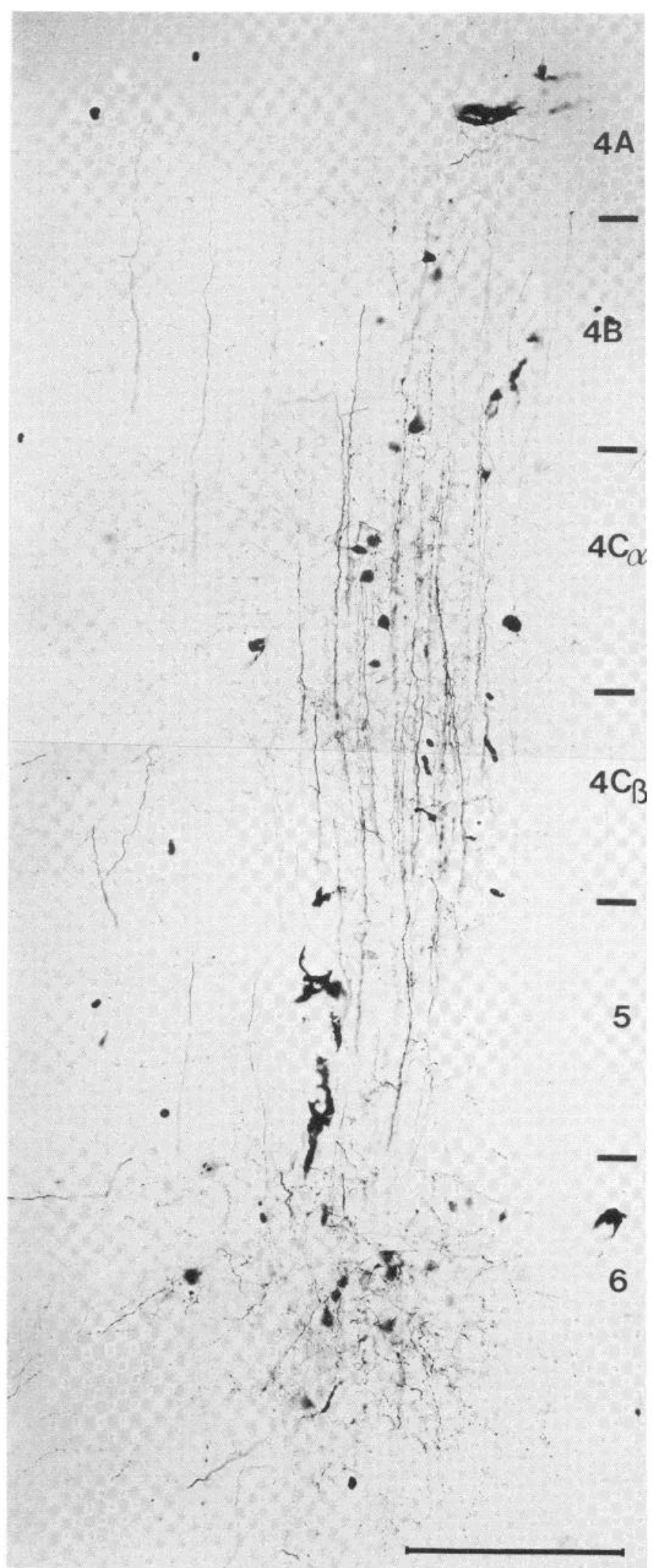

Figure 16. Photomicrograph showing labeled neurons in lamina $4 \mathrm{C} \alpha$ following an injection of HRP into lamina 6. Because of the plane of section, the center of the injection site appears on an adjacent section. Scale bar = $200 \mu \mathrm{m}$. a greater proportion of their terminal arbor to the deeper layers. Another possibility is that descending collaterals from $4 \mathrm{C} \alpha$ might be larger in diameter than those from $4 \mathrm{C} \beta$ neurons and therefore accumulate and transport HRP more readily. Future intracellular injection studies should be able to test these hypotheses.

Projections from other layers to lamina $4 \mathrm{C}$. The major source of intrinsic input to lamina $4 \mathrm{C}$ arises from neurons in lamina 6 . This finding supports previous Golgi studies which showed that many pyramidal neurons in layer 6 have recurrent axon collaterals terminating in lamina 4C (Lund, 1973; Lund and Boothe, 1975). The present results demonstrate that the axons of layer 6 neurons have a morphology that is distinct from that of lateral geniculate afferents. These endings have fine, spine-like protrusions from their surface, unlike the large beaded axon endings associated with geniculate afferents (Blasdel and Lund, 1983). A similar type of axon arbor has been reported for recurrent collaterals of layer 6 pyramidal neurons in the cat (Martin and Whitteridge, 1984; McGuire et al., 1984).

Our experiments do not provide any evidence that the projection to laminae $4 \mathrm{C} \alpha$ and $4 \mathrm{C} \beta$ arises from neurons located at different depths within lamina 6 . Previous studies have suggested that neurons in the upper part of lamina 6 project to $4 C \beta$, whereas those in the lower part project to $4 \mathrm{C} \alpha$, and this difference appeared to correlate with the pattern of descending projections to the magnocellular and parvocellular layers of the LGN (Lund and Boothe, 1975; Lund et al., 1975). Since Golgi studies clearly show neurons in lamina 6 with axon collaterals restricted to $4 \mathrm{C} \alpha$ or $4 \mathrm{C} \beta$, the most reasonable interpretation is that separate populations of neurons in lamina 6 provide input to $4 \mathrm{C} \alpha$ or $4 \mathrm{C} \beta$, but these populations are not rigidly segregated into separate zones within lamina 6 .

Finally, the present results suggest that there is a projection to lamina 4C from neurons within lamina 5A. Previous reports have not described a projection from lamina 5 to lamina $4 \mathrm{C}$ and have emphasized the projection from lamina $5 \mathrm{~A}$ to the more superficial layers of cortex (see Blasdel et al., 1985). Since the neurons in lamina 5A could be labeled because their axons are passing through the injection site to terminate in more superficial layers, and since our anterograde evidence is possibly contaminated by layer 6 afferents, the evidence for this projection is admittedly weak. However, the absence of labeled neurons in lamina $5 \mathrm{~A}$ following injections into lamina $4 \mathrm{C} \beta$ suggests that the labeled cells in lamina $5 \mathrm{~A}$ after $4 \mathrm{C} \alpha$ injections are not due to uptake by passing fibers. Perhaps this projection originates predominently from smooth dendritic neurons in lamina $5 \mathrm{~A}$ whose axons have not yet been described in Golgi studies.

Relation of intrinsic connections to known physiology. One way to shed light on the functional significance of the connections we have described is to consider how they might be related to some of the obvious laminar differences in the physiological response properties of cortical neurons. One way in which cortical layers differ is in the sizes and shapes of the receptive fields of their neurons. Some layers (e.g., laminae $4 \mathrm{C} \beta, 4 \mathrm{~A}$ ) are populated by neurons with very small circular- or ovoidal-shaped receptive fields that are not sensitive to the orientation of a stimulus. Other layers have neurons with larger receptive fields that display orientation selectivity (Hubel and Wiesel, 1968; Bullier and Henry, 1980; Blasdel and Fitzpatrick, 1984).

Another difference between layers concerns the spatial organization of activity related to the two eyes. The major input laminae (4C $\alpha, 4 \mathrm{C} \beta$, and $4 \mathrm{~A}$ ) each consist of two separate and interdigitated monocular "maps" of the visual field, one for each eye. These separate maps are the consequence of a continued segregation of the inputs from different laminae of the LGN (Hubel and Wiesel, $1968,1972)$. In contrast, the major output laminae consist of a single binocular map of the visual field. Although there is a systematic variation in the strengths of the inputs from both eyes, many of the neurons in these efferent layers respond to stimuli presented to either eye. 

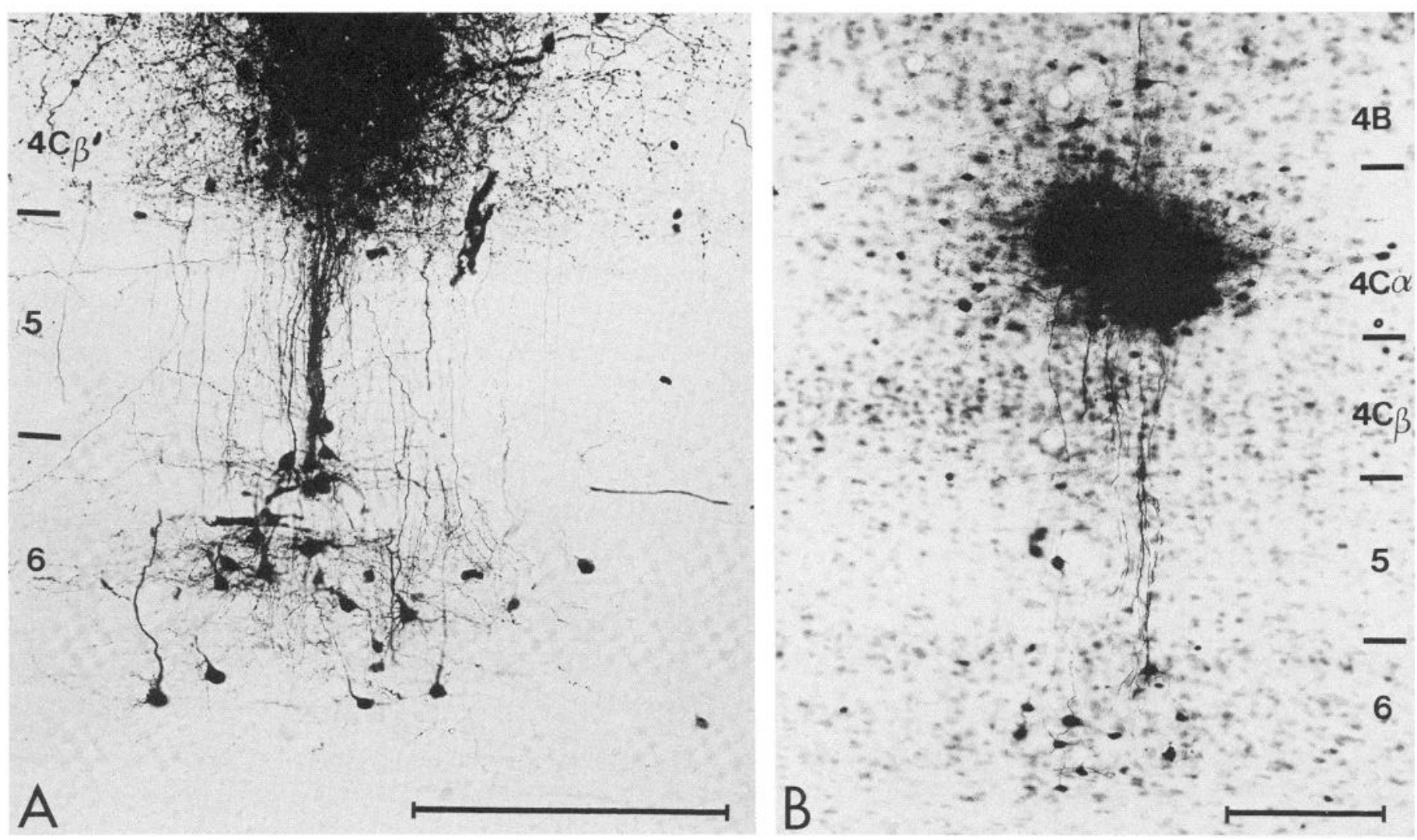

Figure 17. A, Photomicrograph showing the distribution of labeled neurons immediately beneath an injection of HRP into lamina 4C $\beta$. Note the absence of labeled neurons in lamina 5 and the darkly labeled neurons in lamina 6 . Scale bar $=200 \mu \mathrm{m}$. B, Photomicrograph showing labeled neurons in lamina 6 following an HRP injection into lamina $4 \mathrm{C} \alpha$. Note also single-labeled neurons in lamina 5 and in $4 \mathrm{C} \beta$. Scale bar $=200 \mu \mathrm{m}$.

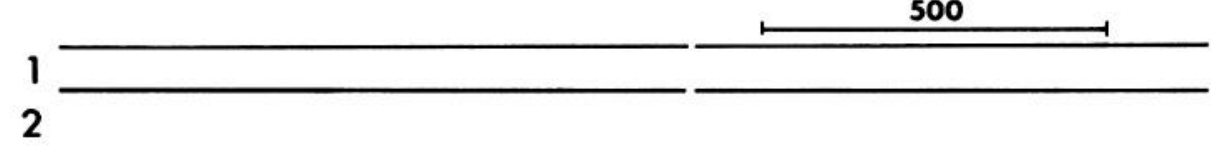

3
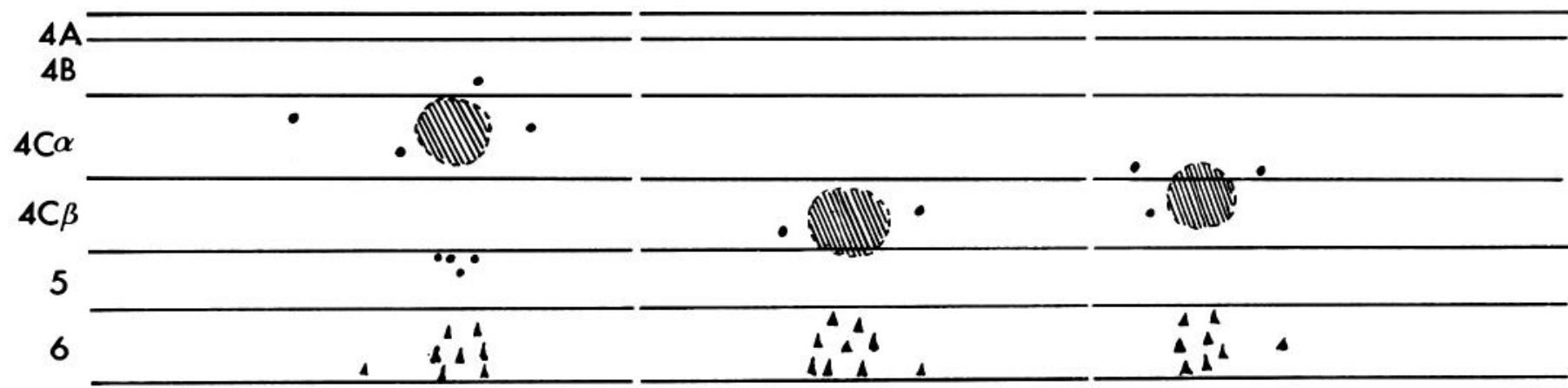

A

B

C

Figure 18. Summary diagram showing the pattern of labeled neurons following HRP injections into laminae $4 \mathrm{C} \alpha(A)$ and $4 \mathrm{C} \beta(B$ and $C)$. Note that there are retrogradely labeled neurons in $5 \mathrm{~A}$ only when the injection is centered in $4 \mathrm{C} \alpha$. 


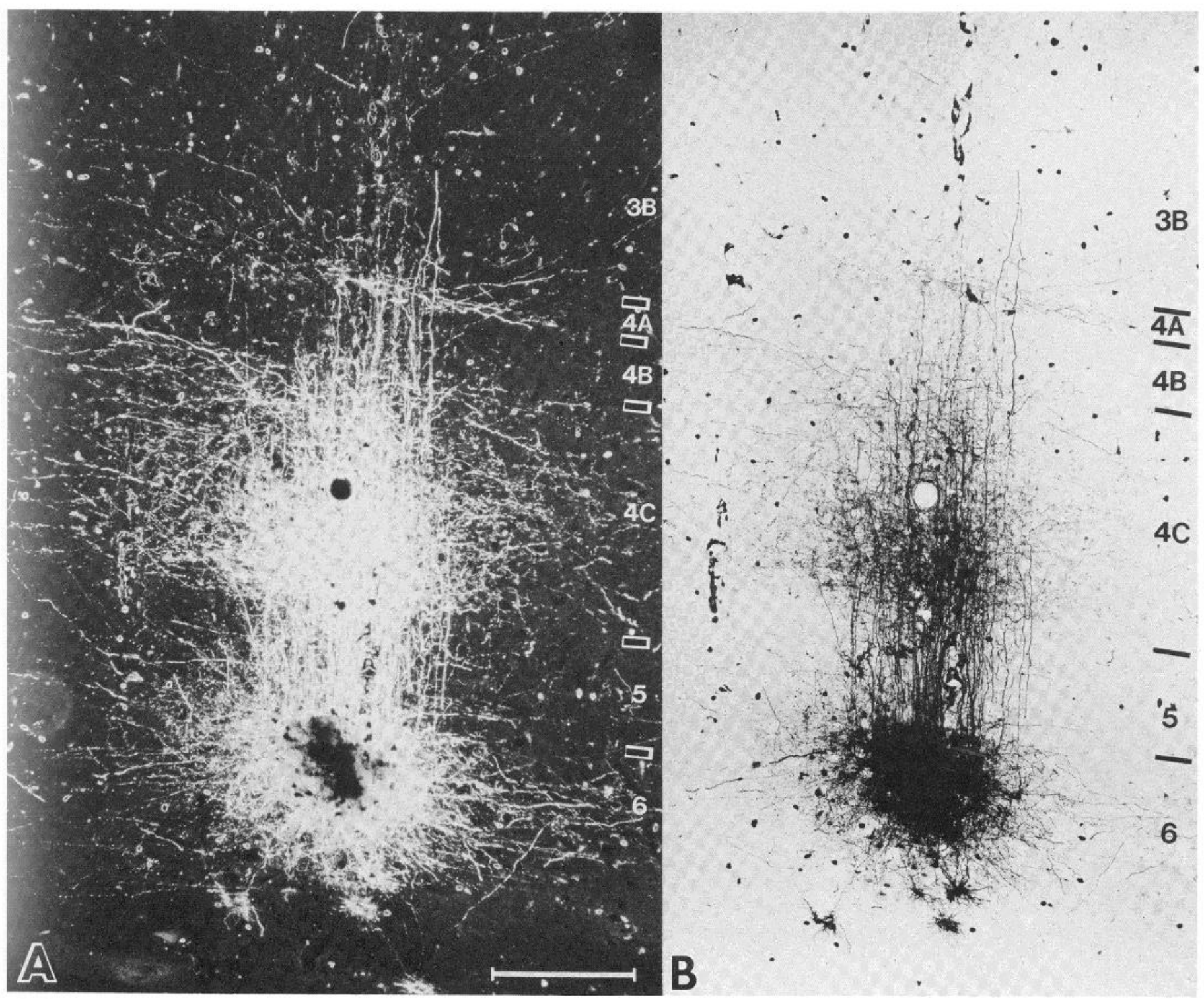

Figure 19. Darkfield $(A)$ and brightfield $(B)$ photomicrographs of an injection into lamina 6 . Note the dense terminal field within laminae $4 \mathrm{C} \alpha$, $4 \mathrm{C} \beta$, and also 4 A. Scale bar $=200 \mu \mathrm{m}$. 


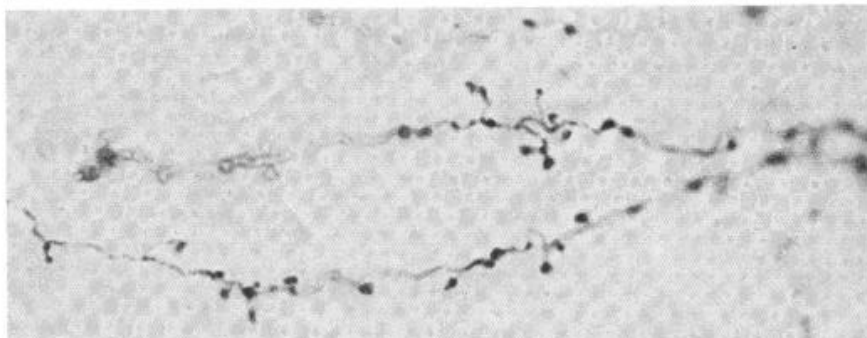

A

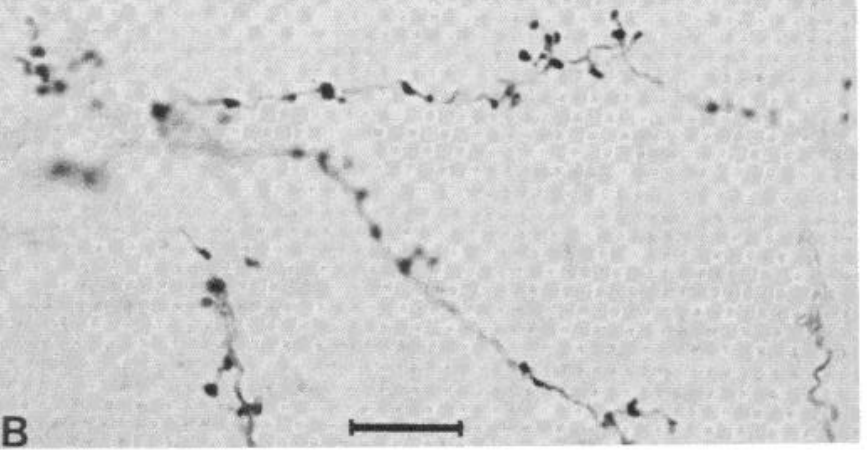

Figure 20. High power photomicrograph showing the delicate side-spine morphology of layer 6 axon terminals in lamina $4 \mathrm{C}$. These axons were labeled with HRP following an injection restricted to lamina 6. Scale bar $=10 \mu \mathrm{m}$.

It makes sense to assume that the connections between a layer with small monocular receptive fields and one with larger binocular fields must involve some amount of anatomical divergence. But this divergence could be contributed by: (1) the lateral spread of interlaminar axons, (2) the lateral spread of postsynaptic dendrites, or (3) lateral connections within the recipient layer. Undoubtedly, all of these factors make a contribution, but from the present data we can consider the contribution made by the lateral spread of the interlaminar axons. To do this we need some way to bring together the information we have about the dimensions of the physiologically defined maps in different layers and the extent of the interlaminar axonal spread that we have described.

The concept of a "point image" provides the basis for such a comparison. A neural point image (Mcllwain, 1976) refers to the amount of cortical area that is functionally connected with a single point in the visual field. Physiologically, the point image is determined by calculating the distance an electrode must be moved across the cortical surface in order to reach a new, nonoverlapping part of the visual field. This distance is dependent on the size and scatter of the neurons' receptive fields and on the local magnification factor. Since there are differences in the sizes of the receptive fields of neurons in different layers, the size of a point image will vary accordingly, lamina $4 \mathrm{C}$ having the smallest point image and other layers, probably lamina 5 and 6 , the largest.

If the activity in one layer is directly reflected in the receptive field properties of a recipient layer, then it makes sense that the extent of divergence in the connections between them (including the contributions from the interlaminar relay axons, postsynaptic dendrites, and lateral intrinsic connections) should be roughly equal to the difference in the size of the point images in the two layers. We have chosen to look at the contribution of the interlaminar relays by comparing the extent of the projections from lamina $4 \mathrm{C} \beta$ to the superficial layers with the sizes of the point images in these regions.

From our microelectrode mapping studies of lamina $4 \mathrm{C} \beta$, we have estimated that, at an eccentricity of 5 to $8^{\circ}$, an electrode must travel
$290 \mu \mathrm{m}$ in order to enter a nonoverlapping part of the visual field (Blasdel and Fitzpatrick, 1984). For the purposes of this argument we will use this linear distance as a measure of the point image rather than to derive an areal figure. Because lamina $4 C$ is divided into separate maps for each eye, a single point in the visual field will actually be represented by two zones of activity within lamina $4 \mathrm{C}$. For simplicity's sake we will double the size of the point image, realizing that, because of the overlapping pattern of retinotopic mapping that occurs in adjacent ocular dominance columns, this figure may slightly underestimate the true value (Hubel and Wiesel, 1977). By combining the point image in lamina $4 C \beta$ with the pattern of projections out of this layer to more superficial layers, we can estimate the size of the afferent plexus in laminae $4 A$ and $3 B$ that corresponds to this point image.

The projections from lamina $4 C \beta$ to lamina $4 A$ appear to be rather restricted in their horizontal extent (i.e., single points in $4 C \beta$ appear to project in a precise vertical fashion upon lamina 4A). Thus, we would predict that the afferent plexus map in lamina $4 \mathrm{~A}$ would be roughly equivalent to that in $4 \mathrm{C} \beta$ and that the information from adjacent ocular dominance columns in lamina $4 \mathrm{C} \beta$ remains largely segregated within lamina $4 \mathrm{~A}$. This pattern of connections is consistent with the fact that most neurons in lamina 4A appear to have monocular response properties (Blasdel and Fitzpatrick, 1984), and the fact that direct inputs from the LGN to lamina $4 \mathrm{~A}$ are segregated into ocular dominance bands in register with those in lamina $4 \mathrm{C}$ (Hubel and Wiesel, 1972; Hendrickson et al., 1978).

In contrast, there appears to be more divergence in the projections from lamina $4 \mathrm{C} \beta$ to lamina $3 \mathrm{~B}$, and we estimate that a single point in lamina $4 \mathrm{C} \beta$ may give rise to axons which spread horizontally up to $400 \mu \mathrm{m}$ within lamina 3B. If we assume that this spread is relatively uniform, then the point image in lamina $4 \mathrm{C} \beta$ will be spread over a region roughly $1 \mathrm{~mm}$ in diameter within lamina $3 \mathrm{~B}$. Because of this lateral spread, it seems likely that the activity relating to individual eyes would no longer be spatially segregated; there would be a region within lamina $3 \mathrm{~B}$ where $4 \mathrm{C} \beta$ axons that are driven by the left and right eyes overlap.

Since our goal is to estimate the full extent of the spread of activity from lamina $4 \mathrm{C}$ within the superficial layers, we need to consider the axonal spread from lamina $3 B$ to more superficial layers. In the following paper (Blasdel et al., 1985) we show that injections of HRP into lamina $4 \mathrm{~A} / 3 \mathrm{~B}$ produce a lateral spread of axons within lamina 2-3 up to $750 \mu \mathrm{m}$ from the injection axis. By taking the point image afferent map in lamina $3 \mathrm{~B}$ and assuming a similar spread for all points in the map, we calculate that the area in lamina 2-3 receiving information relayed from a point image in lamina $4 \mathrm{C}$ is roughly 2.4 $\mathrm{mm}$.

This value compares favorably with the size of the physiologically determined point image in lamina 2-3 reported by Hubel and Wiesel (1974) (2 to $3 \mathrm{~mm}$ ) and with the average size of the point image for all cortical layers reported by Dow et al. (1981) for a comparable eccentricity. Thus, even though we have only considered axonal spread and we view our figures as minimal estimates, interlaminar axonal spread alone appears to be sufficient to account for the difference in the size of the physiologically defined point images in lamina $4 \mathrm{C}$ and in the superficial layers.

An issue that we have not addressed is whether the divergence between lamina $4 \mathrm{C} \beta$ and more superficial layers varies with eccentricity. Our injections were placed into the dorsomedial part of exposed striate cortex and did not extend into the representation of the fovea. Recent physiological studies suggest that the size of the point image is not uniform for all eccentricities but increases significantly within the foveal representation (Dow et al., 1981; Van Essen et al., 1984). It seems likely that the lateral extent of interlaminar connections remains constant throughout striate cortex and that the change in the size of the point image with eccentricity reflects differences in the spread of afferents from the LGN. But this idea needs to be tested, both by evaluating the dimensions of a point image in lamina $4 C \beta$ of foveal striate cortex and by determining the 

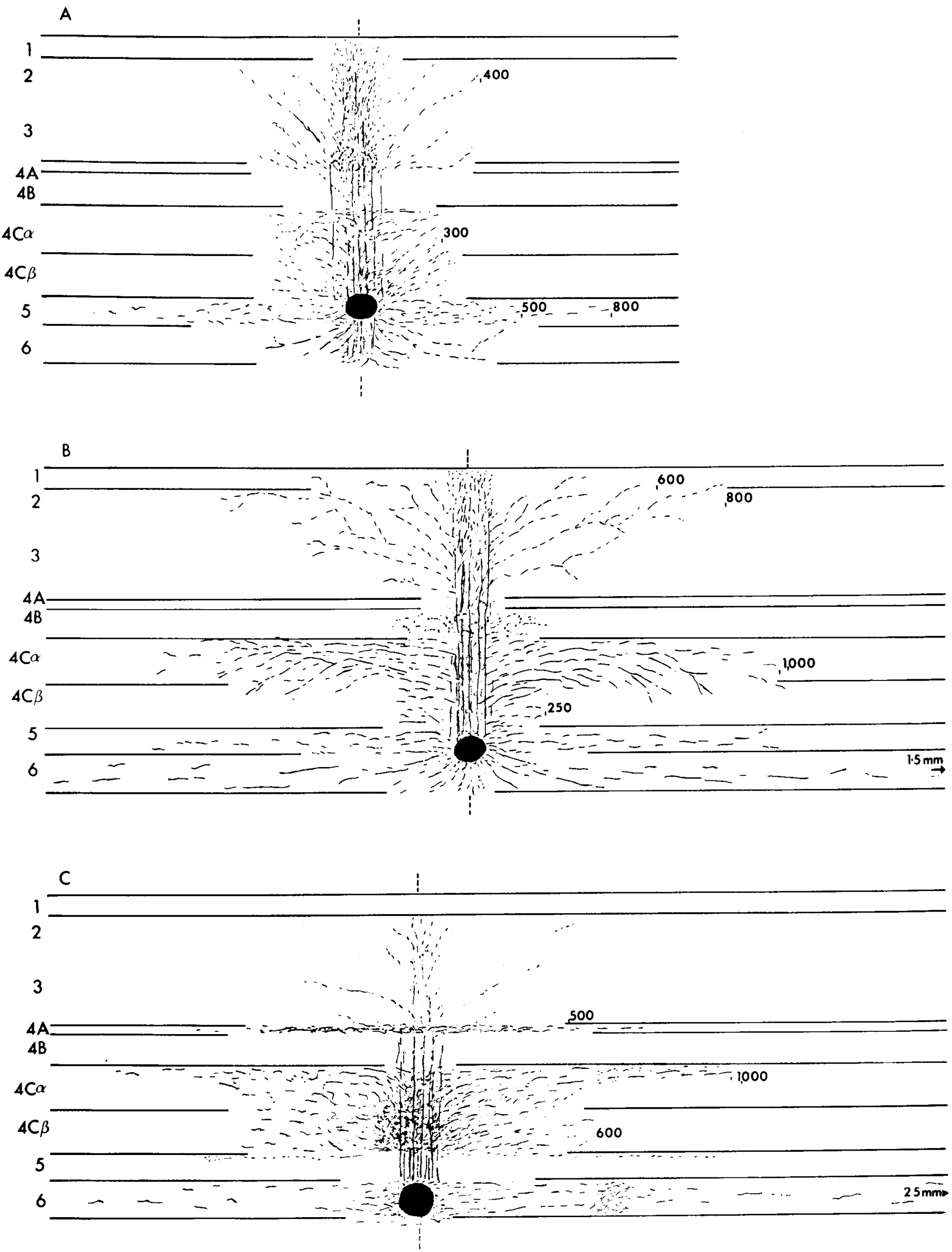

Figure 21. Summary diagram showing the pattern of HRP-labeled axons and terminals following injections into lamina $5(A)$, the $5-6$ border region $(B)$, and lamina $6(C)$ 

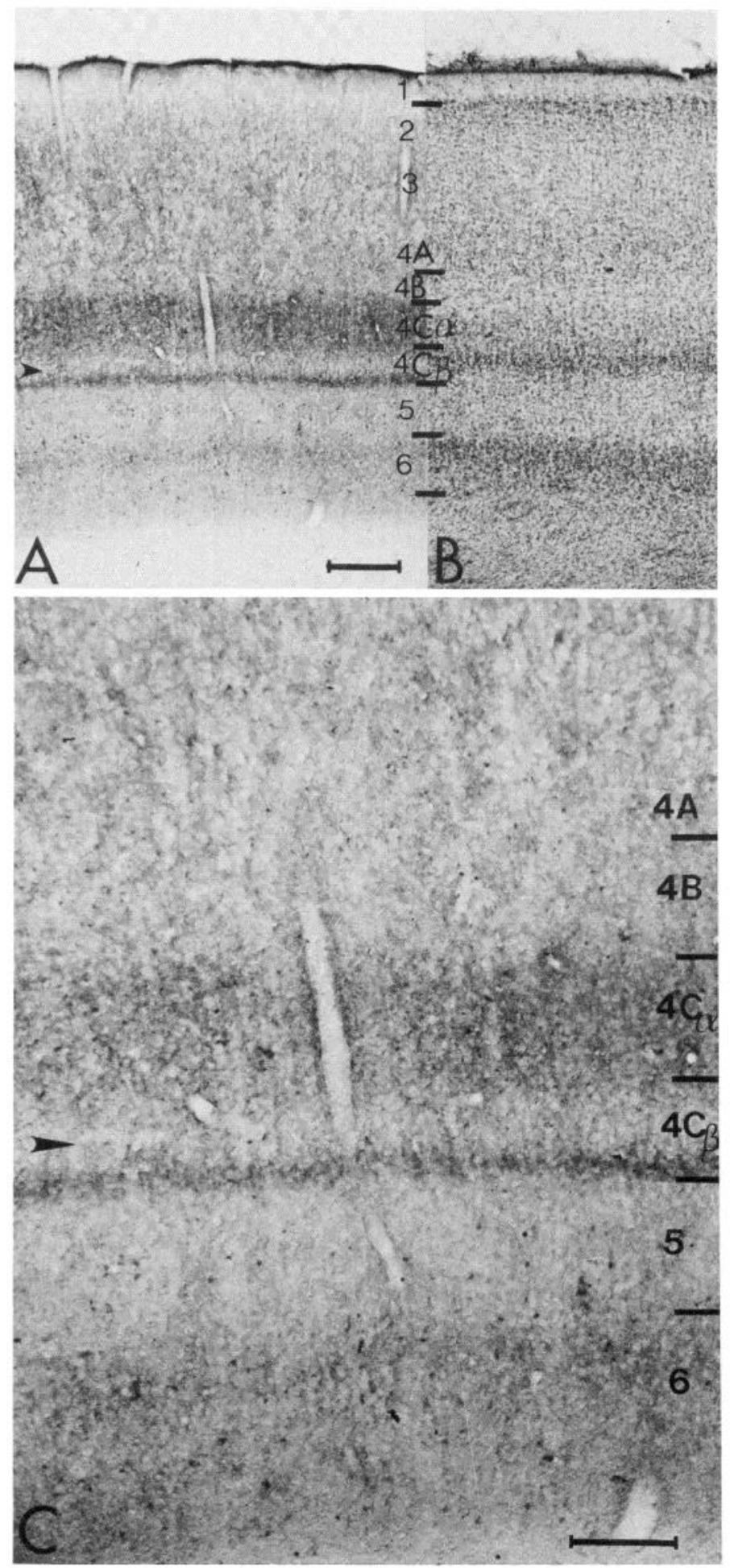

Figure 22. Cytochrome oxidase-reacted $(A$ and $C$ ) and Nissl-stained $(B)$ sections of 16-day-old infant rhesus monkey striate cortex. Unlike the adult monkey in which layer $4 \mathrm{C}$ stains evenly through its depth for cytochrome oxidase (see Fig. $1 B$ ), in the infant a light cleft is evident in upper $4 C \beta$ (see higher power view in $C$-the cleft is indicated by arrowheads in $A$ and $C$ ). This light cleft is the most cell-rich portion of $4 \mathrm{C} \beta$. The division of $4 \mathrm{C} \beta$ into cytochrome-rich and cytochrome-poor divisions may be reflected in the adult monkey in terms of a difference in the pattern of axon projections from neurons in upper and lower $4 \mathrm{C} \beta$ to the $3 \mathrm{~B} / 4 \mathrm{~A}$ region (see the text). Scale bars $=200 \mu \mathrm{m}$. extent of axonal connections between $4 \mathrm{C} \beta$ and the superficial layers of cortex.

Finally, although this analysis sheds light on the horizontal extent of the connections between layers, it tells us little about the ways in which response properties of individual neurons (such as orientation selectivity) are derived. These features could be derived from local anisotropies in the distribution of interlaminar axons, the organization of the dendrites of the postsynaptic neurons, ordered connections within the layer, or some combination of these factors. Indeed, we found some evidence for asymmetries in the axonal projections from lamina $4 \mathrm{C} \beta$ to lamina $3 \mathrm{~B}$ and, as we will see in the following paper (Blasdel et al., 1985), some of the layers which have orientationselective neurons have prominent periodic lateral connections (Rockland and Lund, 1983). It seems likely that these features play some role in the generation or elaboration of orientation selectivity-but their exact contribution remains to be determined.

\section{References}

Adams, J. C. (1977) Technical considerations on the use of horseradish peroxidase as a neuronal marker. Neuroscience 2: 141-145.

Blasdel, G. G., and D. Fitzpatrick (1984) Physiological organization of layer 4 in macaque striate cortex. J. Neurosci. 4: 880-895.

Blasdel, G. G., and J. S. Lund (1983) Termination of afferent axons in macaque striate cortex. J. Neurosci. 3: 1389-1413.

Blasdel, G. G., D. Fitzpatrick, and J. S. Lund (1983) Organization and intracortical connectivity of layer 4 in macaque striate cortex. Soc. Neurosci. Abstr. 9: 476.

Blasdel, G. G., J. S. Lund, and D. Fitzpatrick (1985) Intrinsic connections of macaque striate cortex: Axonal projections of cells outside lamina $4 \mathrm{C}$. J. Neurosci. 5: 3350-3369.

Bullier, J., and G. H. Henry (1980) Ordinal position of afferent input of neurons in monkey striate cortex. J. Comp. Neurol. 193: 913-936.

Carroll, E. W., and M. T. T. Wong-Riley (1984) Quantitative light and electron microscopic analysis of cytochrome oxidase-rich zones in the striate cortex of the squirrel monkey. J. Comp. Neurol. 222: 1-17.

de Olmos, J. S. (1977) An improved HRP method for the study of central nervous connections. Exp. Brain Res. 29: 541-551.

Dow, B. M., A. Z. Synder, R. G. Vautin, and R. Bauer (1981) Magnification factor and receptive field size in foveal striate cortex of the monkey. Exp. Brain Res. 44: 213-228.

Fitzpatrick, D., K. Itoh, and I. T. Diamond (1983) The laminar organization of the lateral geniculate body and the striate cortex in the squirrel monkey (Saimiri sciureus). J. Neurosci. 3: 673-702.

Hendrickson, A. E., J. R. Wilson, and M. P. Ogren (1978) The neuroanatomical organizations of pathways between dorsal lateral geniculate nucleus and visual cortex in Old and New World primates. J. Comp. Neurol. 182: 123136.

Horton, J. C. (1984) Cytochrome oxidase patches: A new cytoarchitectonic feature of monkey visual cortex. Philos. Trans. R. Soc. Lond. (Biol.) 304: 199-253.

Hubel, D. H., and T. N. Wiesel (1968) Receptive fields and functional architecture of monkey striate cortex. J. Physiol. (Lond.) 195: 215-243.

Hubel, D. H., and T. N. Wiesel (1972) Laminar and columnar distribution of geniculo-cortical fibers in the macaque monkey. J. Comp. Neurol. 146: 421-450.

Hubel, D. H., and T. N. Wiesel (1974) Uniformity of monkey striate cortex: A parallel relationship between field size, scatter and magnification factor. $\mathrm{J}$. Comp. Neurol. 158: 295-306.

Hubel, D. H., and T. N. Wiesel (1977) Functional architecture of macaque monkey visual cortex. Proc. R. Soc. Lond. (Biol.) 198: 1-59.

Livingstone, M. S., and D. H. Hubel (1984) Anatomy and physiology of a color system in the primate visual cortex. J. Neurosci. 4: 309-356.

Lund, J. S. (1973) Organization of neurons in the visual cortex, area 17, of the monkey (Macaca mulatta). J. Comp. Neurol. 147: 455-496.

Lund, J. S., and R. G. Boothe (1975) Interlaminar connections and pyramidal neuron organization in the visual cortex, area 17, of the macaque monkey. J. Comp. Neurol. 159: 305-334.

Lund, J. S., R. D. Lund, A. E. Hendrickson, A. H. Bunt, and A. F. Fuchs (1975) The origin of efferent pathways from primary visual cortex, area 17, of the macaque monkey as shown by retrograde transport of horseradish peroxidase. J. Comp. Neurol. 164: 287-304. 
Lund, J. S., D. Fitzpatrick, and G. G. Blasdel (1983) Intrinsic connections of macaque striate cortex. Soc. Neurosci. Abstr. 9: 476.

Martin, K. A. C., and D. Whitteridge (1984) Form, function and intracortical projections of spiny neurones in the striate visual cortex of the cat. $\mathrm{J}$. Physiol. (Lond.) 353: 463-504.

McGuire, B. A., J. P. Hornung, C. D. Gilbert, and T. N. Wiesel (1983) Layer 6 cells primarily contact smooth and sparsely spiny neurons in layer 4 of cat striate cortex. Soc. Neurosci. Abstr. 9: 617.

McGuire, B. A., J. P. Hornung, C. D. Gilbert, and T. N. Wiesel (1984) Patterns of synaptic input to layer 4 of cat striate cortex. J. Neurosci. 4: $3021-$ 3033.

Mcllwain, J. T. (1976) Large receptive fields and spatial transformations in the visual system. Int. Rev. Physiol. 10: 223-248.

Mitzdorf, U., and W. Singer (1979) Excitatory synaptic ensemble properties in the visual cortex of the macaque monkey: A current source density analysis of electrically evoked potentials. J. Comp. Neurol, 187: 71-84.

Nauta, H. J. W., A. B. Butler, and J. Jane (1973) Some observations on axonal degeneration resulting from superficial lesions of the cerebral cortex. J. Comp. Neurol. 150: 349-360

Rockland, K. S., and J. S. Lund (1983) Intrinsic laminar lattice connections in primate visual cortex. J. Comp. Neurol. 216: 303-318.

Rockland, K. S., and D. N. Pandya (1979) Laminar origins and terminations of cortical connections of the occipital lobe in rhesus monkey. Brain Res. 179: 3-20.

Tigges, M., and J. Tigges (1983) Cytochrome oxidase staining pattern in area 17: Adult versus neonate monkeys. Invest. Ophthalmol. Vis. Sci. 24: 229.

Tigges, J., M. Tigges, S. Anschel, N. A. Cross, W. D. Letbetter, and R. L. McBride (1981) Areal and laminar distribution of neurons interconnecting the central visual cortical areas 17, 18, 19 and MT in squirrel monkey (Saimiri). J. Comp. Neurol. 202: 539-560.

Valverde, F. (1971) Short axon neuronal subsystems in the visual cortex of the monkey. Int. J. Neurosci. 1: 181-197.

Van Essen, D. C., W. T. Newsome, and J. H. R. Maunsell (1984) The visual cortex representation in striate cortex of the macaque monkey: Asymmetries, anisotropies and individual variability. Vision Res. 24: 429-448. 